Research Article

\title{
Seismic Response of a Tunnel Embedded in Compacted Clay through Large-Scale Shake Table Testing
}

\author{
Hao Zhou $(\mathbb{D}$, Xinghua Wang $\mathbb{D}$, Changdi He, and Changxi Huang \\ Department of Civil Engineering, Central South University, Changsha 410075, China \\ Correspondence should be addressed to Xinghua Wang; xhwang@mail.csu.edu.cn
}

Received 3 May 2018; Revised 17 September 2018; Accepted 20 September 2018; Published 1 November 2018

Academic Editor: Manuel Lopez Aenlle

Copyright (c) 2018 Hao Zhou et al. This is an open access article distributed under the Creative Commons Attribution License, which permits unrestricted use, distribution, and reproduction in any medium, provided the original work is properly cited.

\begin{abstract}
To investigate the seismic response of large-scale tunnel in compacted clay and effect of shock absorbing layer to the tunnel, a series of three dimensional (3D) shaking table model tests were carried out. The similarity ratio of the model is $1: 8$ and the size of the model container is $9.3 \mathrm{~m}$ (length) $\times 3.7 \mathrm{~m}$ (width) $\times 2.5 \mathrm{~m}$ (height). The cross-sectional diameter of the model tunnel is $0.9 \mathrm{~m}$, and the thickness of the tunnel lining is $0.06 \mathrm{~m}$. To simulate the clay soil surrounding condition, the container was filled with clay soil. During the tests, the concrete strain, acceleration, and dynamic soil pressure on the surface of the model tunnel were measured. The results show the existence of tunnel can decrease the maximum acceleration of the model in the $X$ direction; the shock absorbing layer can further decrease the maximum acceleration, however, cannot change the dominant frequency of the ground motion. The longitudinal and hoop strain of the model tunnel with excitation of the input motion is mainly in tension state and the maximum hoop deformation of the model tunnel is located at the conjugate $45^{\circ}$. In addition, the shock absorbing layer has an effect on the strain and dynamic earth pressure of the model tunnel.
\end{abstract}

\section{Introduction}

Tunnel behaved better than above ground structure during the earthquake loading. However, earthquake events in recent years show that the underground structure has serious damage in seismically active area; for example, the collapse of the Daikai subway metro station in Kobe, in Japan (1995) [1]; failure of Bolu tunnel in Turkey (1999) [2]; damage of LongXi tunnel in WenChuan (2008) [3]. These failures revealed that the current practices of seismic design for underground structures cannot ensure the seismic performance of tunneling structures. Therefore, how to improve safety of tunnels during earthquakes has become one of the major concerns for the engineering.

Many scholars have investigated the seismic response of tunnel during the earthquake loading through theoretical analysis [4-11], which has a certain significance of engineering guiding in seismic of tunnel. However, the results of these methods may substantially deviate, even under the same assumptions. Therefore, it is a better way to find the weakness parts of tunnels and explore the structure of the failure mechanism of tunnels through the model test. Cheng et al. [12] found that soil liquefaction significantly influenced the propagation of seismic motions and the dynamic responses of the tunnel. Ulas et al. [13] carried out dynamic centrifuge modeling to circular tunnel in dry clay (scale 1 : 50); largest axial dynamic lining forces were measured near shoulders. Tsinidis et al. [14] found the horizontal acceleration recorded at several locations was generally amplified towards the soil surface of square tunnel in dry clay, while the tunnel presence affected this amplification (scale $1: 50$ ). Tsinidis et al. [15] revealed a minor effect of the interface properties on the tunnels racking deformation (scale $1: 40$ ). Jiang et al. [16] found that the soil pressures were symmetrically distributed on the left and right side walls. Cilingir and Madabhushi [17] conducted centrifuge modeling of square tunnel to investigate the effect of different shallow depths of clay deposits. The results show that the depth of the tunnel does not affect the deformation pattern of the tunnel significantly during an earthquake event (scale 1:45). The above literature of model tests has a common feature, that is, the small scale model testing, which has a certain value for investigating the seismic response of tunnel. However, these small-scale model tests can oversimplify the complexity of the 
detail and response characteristic of a tunnel structure. It is even more difficult to show the realistic response to the lining force and failure characteristics of the tunnel. Moreover, Andrew [18] found that as the difference in the scales of the model and prototype increases, the difference in the threedimensional and time-varying properties also increases. Therefore, based on reducing the difference brought by the small scale and the influence of boundary effects, in order to investigate the dynamic response of a tunnel and the soiltunnel interaction, it is necessary to carry out the shake table test of large-scale $(1: 8)$ shield tunneling models in a $9.3 \mathrm{~m}$ long, $3.7 \mathrm{~m}$-wide, and $2.5 \mathrm{~m}$-high rigid box.

The objectives of this study are (a) to provide experimental data on the seismic response of circular tunnels in compacted clay with ground motions excitation; (b) to determine the differences in the measured accelerations, strains, and dynamic earth pressures between the cross sections with and without a shock absorbing layer (SAL); (c) to evaluate the efficiency of the SAL during earthquake loadings. In this paper, a series of shake table tests on largescaled circular model tunnel embedded in clay soil are initially presented. The tests were conducted at Shake table laboratory of National Engineering Laboratory for Construction Technology of High Speed Rail in China. Following a detailed description of the experimental set up, a detailed description of the experimental setup is provided, focusing on the design of the soil container, clay soil tested and the scaled model tunnel, instrumentation, and test procedure. The main results obtained from the tests are summarized and discussed experiment measurements in terms of concrete strain, dynamic earth pressure, and acceleration. The collected experimental data are primarily to be used to better understand the seismic behavior of circular tunnel and further optimizing seismic design methods for tunnels.

\section{Test Setup and Model Preparation}

2.1. Shake Table System. The shake table tests were performed using the Laboratory Multifunction Shaking Table System (LMSTS) in the National Engineering Laboratory of High Speed Railway Construction Technology in Central South University, China. The LMSTS has an electrohydraulic servo drive, and it consists of three $4 \mathrm{~m} \times 4 \mathrm{~m}$ 6-DOF mobile stations, in which can be controlled independently to simulate single or multiple three-directional ground motions. The LMSTS was built in 2009 and equipped with the advanced instruments high-performance dynamic signal acquisition system, which carry out independent sampling of 320 input channels for accelerometers, strain gauges, and earth pressure sensors. Figure 1 shows the layout of LMSTS and the horizontal and vertical actuators. For the tests conducted in this study, only Tables A and B were used. Main parameters of shake table facility are summarized in Table 1 .

\subsection{The Soil Container}

2.2.1. Design of Soil Container. The soil container is a rigid box with the dimensions of $9.3 \mathrm{~m}$ (length) $\times 3.7 \mathrm{~m}$ (width) $\times$ $2.5 \mathrm{~m}$ (height), as shown in Figure 2. The soil container



(a)

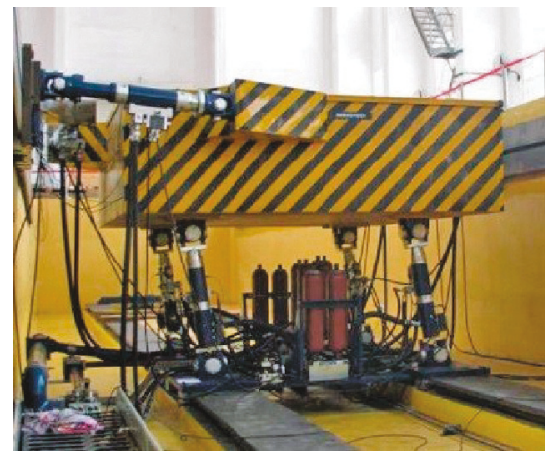

(b)

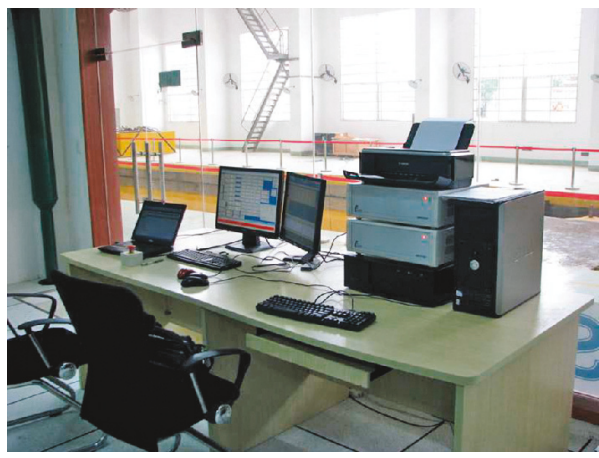

(c)

FIGURE 1: Laboratory multifunction shaking table system. (a) Three tables and horizontal actuators. (b) Vertical actuators. (c) Control system.

includes the box wall, the inner framework, and the outer framework. The box wall was made by steel plates and the thickness of the plates is $6 \mathrm{~mm}$. The inner framework consists of steel strips welded onto the box wall to ensure the box is rigid; the outer framework consists of steel angles welded between steel plates. Two transverse ribs were welded onto the top of the model container. The bottom of the box is a $5 \mathrm{~mm}$ thick steel plate welded on to the frame. The inner bottom of the box was divided into $1.0 \mathrm{~m}^{2}$ baffle plates using welded steel angles. The total weight of the empty box is $3,800 \mathrm{~kg}$, approximately. The soil container was bolted firmly onto tables $\mathrm{A}$ and $\mathrm{B}$ using a total of 64 high-strength bolts. The length/height ratio of the container is 3.72, and this design can reduce the boundary effect of the rigid end wall $[19,20]$.

2.2.2. Boundary Condition. The boundary condition is crucial for the result of the shake table tests and a waveabsorbing boundary condition is needed. The flexible 
TABLE 1: Main parameters of shake table facility.

\begin{tabular}{|c|c|c|c|}
\hline Technical parameter & Table A & Table B & Table C \\
\hline Table size $(\mathrm{m} \times \mathrm{m})$ & $4 \times 4$ & $4 \times 4$ & $4 \times 4$ \\
\hline $\begin{array}{l}\text { Maximum specimens } \\
\text { weight (ton) }\end{array}$ & 35 & 35 & 35 \\
\hline $\begin{array}{l}\text { Maximum overturning } \\
\text { moment }(\text { ton } \cdot \mathrm{m})\end{array}$ & 35 & 35 & 35 \\
\hline $\begin{array}{l}\text { Maximum turning } \\
\text { moment (ton } \cdot \mathrm{m})\end{array}$ & 20 & 20 & 20 \\
\hline $\begin{array}{l}\text { Range of operating } \\
\text { frequency }(\mathrm{Hz})\end{array}$ & $0.1-50$ & $0.1-50$ & $0.1-50$ \\
\hline $\begin{array}{l}X \text { direction moving } \\
\text { distance }(\mathrm{m})\end{array}$ & 0.0 & $5.0-20.0$ & $5.0-20.0$ \\
\hline $\begin{array}{l}X \text { direction maximum } \\
\text { displacement }(\mathrm{mm})\end{array}$ & 250 & 250 & 250 \\
\hline $\begin{array}{l}Y \text { direction maximum } \\
\text { displacement }(\mathrm{mm})\end{array}$ & 250 & 250 & 250 \\
\hline $\begin{array}{l}Z \text { direction maximum } \\
\text { displacement }(\mathrm{mm})\end{array}$ & 160 & 160 & 160 \\
\hline $\begin{array}{l}X \text { direction maximum } \\
\text { velocity }(\mathrm{mm} / \mathrm{s})\end{array}$ & $X: \pm 1000$ & $X: \pm 1000$ & $X: \pm 1000$ \\
\hline $\begin{array}{l}Y \text { direction maximum } \\
\text { velocity }(\mathrm{mm} / \mathrm{s})\end{array}$ & $Y: \pm 1000$ & $Y: \pm 1000$ & $Y: \pm 1000$ \\
\hline $\begin{array}{l}Z \text { direction maximum } \\
\text { velocity }(\mathrm{mm} / \mathrm{s})\end{array}$ & $Z: \pm 1000$ & $Z: \pm 1000$ & $Z: \pm 1000$ \\
\hline $\begin{array}{l}X \text { direction maximum } \\
\text { acceleration }(\mathrm{g})\end{array}$ & $X: \pm 1.0$ & $X: \pm 1.0$ & $X: \pm 1.0$ \\
\hline $\begin{array}{l}Y \text { direction maximum } \\
\text { acceleration }(\mathrm{g})\end{array}$ & $Y: \pm 1.0$ & $Y: \pm 1.0$ & $Y: \pm 1.0$ \\
\hline $\begin{array}{l}Z \text { direction maximum } \\
\text { acceleration }(\mathrm{g})\end{array}$ & $Z: \pm 1.6$ & $Z: \pm 1.6$ & $Z: \pm 1.6$ \\
\hline Motion Dofs & $\begin{array}{l}6 \text { Dofs in } \\
3 \text { direction }\end{array}$ & $\begin{array}{l}6 \text { Dofs in } \\
3 \text { direction }\end{array}$ & $\begin{array}{l}6 \text { Dofs in } \\
3 \text { direction }\end{array}$ \\
\hline
\end{tabular}



Figure 2: The soil container.

materials are generally installed inside the rigid container to reduce the boundary effect of the box wall during shake table tests and these flexible materials are usually polystyrene foam boards and sponge rubber [21-24]. In this study, a $10 \mathrm{~cm}$-thick polystyrene foam board was attached to the container walls; meanwhile, a $5 \mathrm{~cm}$-thick and a $2.5 \mathrm{~cm}$-thick sponge rubber boards were attached to the end walls and the side walls, respectively.

2.3. Model Tunnel and Materials. The model tunnel is scaled at $1: 8$. The prototype tunnel has a cross-sectional diameter of $7.2 \mathrm{~m}$ and a lining thickness of $0.48 \mathrm{~m}$. According to the
TABLE 2: Similarity ratios of the model to prototype.

\begin{tabular}{lcc}
\hline Physical parameter & Similarity relationship & Similarity ratio \\
\hline Geometry & $C_{\mathrm{l}}$ & $1 / 8$ \\
Density & $C_{\rho}$ & $4 / 5$ \\
Elastic module & $C_{\mathrm{E}}$ & $1 / 10$ \\
Strain & $C_{\varepsilon}$ & 1 \\
Stress & $C_{\sigma}=C_{\mathrm{E}} \times C_{\varepsilon}$ & $1 / 10$ \\
Acceleration & $C_{\mathrm{a}}$ & 1 \\
Poisson's ratio & $C_{v}$ & 1 \\
Friction angle & $\Phi$ & 1 \\
Frequency & $C_{\mathrm{f}}=C_{1}^{-1}\left(C_{\mathrm{E}} / C_{\rho}\right)^{1 / 2}$ & 2.828 \\
Time & $C_{\mathrm{t}}=C_{1}^{1 / 2}$ & 0.354 \\
\hline
\end{tabular}

similarity law [25], the cross-sectional diameter of the model tunnel is $0.9 \mathrm{~m}$ and the thickness of the tunnel lining is $0.06 \mathrm{~m}$. Table 2 shows the similarity ratios of the model tunnel.

The steps of how to install the model tunnel and tamper the clay soil are as follow:

Firstly, at the base of the soil container, a layer of $2-3 \mathrm{~cm}$ diameter aggregate was placed to increase the frictional resistance between the model clay and the floor to reduce potential slippage.

Secondly, the clay soil was placed into soil container and the thickness of rammed layer is $20 \mathrm{~cm}$. When the clay soil was buried to a height of $30 \mathrm{~cm}$, nine model tunnels were installed in the middle of the soil container along the $X$ direction. The clay soil was compacted to the height of $191 \mathrm{~cm}$, which mainly simulated the dynamic response of the shield tunnel in clay stratum. The clay soil was brought from YueLu Mountain, and its properties were tested using samples taken directly from the soil container [26, 27]. Table 3 shows the physical properties of the compacted clay.

As shown in Figure 3, on the basis of equivalent stiffness principle, the tunnel lining is made of microconcrete with an inside diameter of $0.78 \mathrm{~m}$ and a thickness of $0.06 \mathrm{~m}$. It is reinforced with steel mesh ( $6 \mathrm{~mm}$ diameter) at the radial ring spacing of $10 \mathrm{~mm}$. Table 4 shows the typical mechanical properties of the model tunnel used in the tests. A $5 \mathrm{~cm}$-thick foam board was used to wrap a section of the model tunnel (Figure 4) to investigate the effect of the SAL on the tunnel response under seismic shaking, and previous dynamic finite difference method revealed that $5 \mathrm{~cm}$-thick foam board can significantly reduce the seismic dynamic response of the second lining of tunnels. The shake table tests also revealed that the strains of lining are reduced by the SAL [28-30]. Table 5 shows the mechanical properties of the foam board.

2.4. Measuring Devices and Instrumentation Layout. Three sets of sensors were installed on the model tunnel to monitor the model tunnel seismic response during the tests; the measuring rang and minimum precision of the capacitive micromachined accelerometers (model 2210 by Vigor, T., Ltd.) are $\pm 2 \mathrm{~g}$ and $0.001 \mathrm{~g}$, respectively, and the measuring rang of microresistance strain earth pressure cells (Zhuochuan Electronic Technology of Beijing Co., Ltd) is $\pm 300 \mathrm{kPa}$ and the minimum precision is $0.001 \mathrm{kPa}$; the resistance 
TABle 3: Physical properties of clay soil [26, 27].

\begin{tabular}{|c|c|c|c|c|c|c|}
\hline $\begin{array}{l}\text { Dry density } \\
\left(\mathrm{g} / \mathrm{cm}^{3}\right)\end{array}$ & $\begin{array}{c}\text { Cohesive strength } \\
(\mathrm{kPa})\end{array}$ & $\begin{array}{c}\text { Internal friction } \\
\text { angle }\left({ }^{\circ}\right)\end{array}$ & $\begin{array}{c}\text { Water content } \\
(\%)\end{array}$ & $\begin{array}{l}\text { Poisson's } \\
\text { ratio }\end{array}$ & $\begin{array}{l}\text { Plasticity } \\
\text { index }\end{array}$ & $\begin{array}{c}\text { Liquidity } \\
\text { index }\end{array}$ \\
\hline 1.67 & 55.76 & 24.74 & 19.3 & 0.37 & 7.68 & 0.21 \\
\hline
\end{tabular}

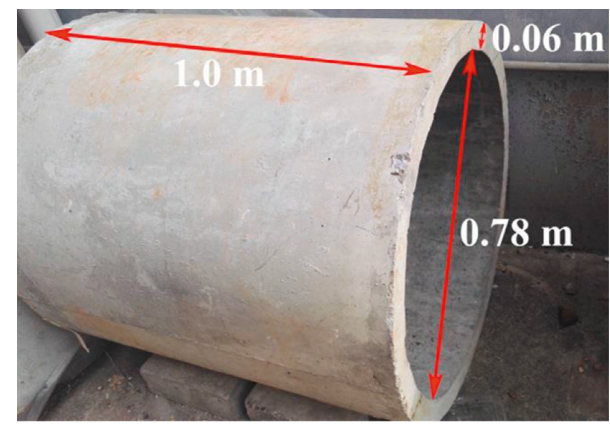

FIGURE 3: Model tunnel.

TABLE 4: Model tunnels mechanical properties [27].

\begin{tabular}{lccc}
\hline $\begin{array}{l}\text { Unit weight } \\
\rho_{\mathrm{t}}\left(\mathrm{kg} / \mathrm{m}^{3}\right)\end{array}$ & $\begin{array}{c}\text { Elastic modulus, } \\
E_{\mathrm{t}}(\mathrm{GPa})\end{array}$ & $\begin{array}{c}\text { Poisson's } \\
\text { ratio, } v_{\mathrm{t}}\end{array}$ & $\begin{array}{c}\text { Yield strength, } \\
f_{\mathrm{y}}(\mathrm{MPa})\end{array}$ \\
\hline 1900 & 3 & 0.23 & 6 \\
\hline
\end{tabular}

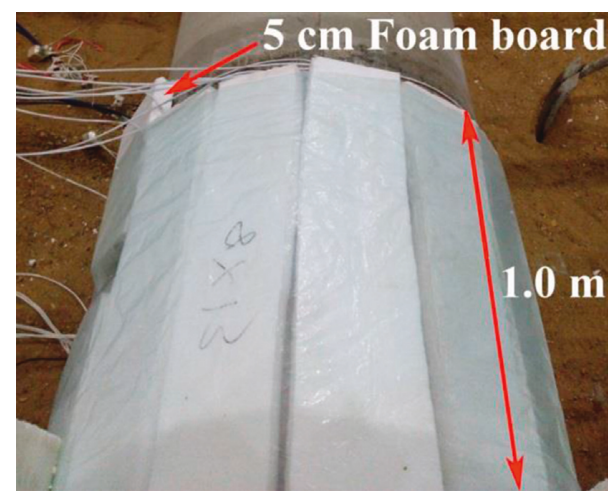

FIgURE 4: Shock absorbing layer.

TABLE 5: Mechanical properties of foam board.

\begin{tabular}{lccc}
\hline $\begin{array}{l}\text { Density } \\
\rho_{\mathrm{f}}\left(\mathrm{kg} / \mathrm{m}^{3}\right)\end{array}$ & $\begin{array}{c}\text { Young's modulus, } \\
E_{\mathrm{f}}(\mathrm{kPa})\end{array}$ & $\begin{array}{c}\text { Poisson's } \\
\text { ratio, } \nu_{\mathrm{f}}\end{array}$ & $\begin{array}{c}\text { Damping, } \\
\xi(\%)\end{array}$ \\
\hline 12 & 16 & 0.29 & 24 \\
\hline
\end{tabular}

strain gauges (model BX120-100AA, Taizhou Technology Co., Ltd) has a measuring rang of about $0 \sim 12000 \mu \varepsilon$ and the minimum presion is $0.001 \mu \varepsilon$. Figure 5 shows the layout of the instrumentation.

As shown in Figure 5(a), two main cross-sections were designed for monitoring in the soil container. One is the cross section \# 1 which has one model tunnel, the other is the cross section \# 2 which has one model tunnel wrapped by a $5 \mathrm{~cm}$-thick foam board. As shown in Figure 5(b)-5(c), three sets of sensors have been installed in the rigid box. The first set of accelerometers is used to measure the accelerations in the $X, Y$, and $Z$ directions of tunnel lining. The second set is used to measure the accelerations of the model clay, and the third set is used to measure the accelerations on the shake table. The dynamic earth pressure cells are installed to measure the earth pressure at the interface of the clay, and the strain gauges are installed to measure the deformation of the inner and outer surfaces of the model tunnel.

2.5. Experimental Program and Test Procedure. During the tests, white noise and harmonic motions frequency sweeps and the recorded earthquake input motions were used. White noise sweep can determine the approximate range of the natural frequency of the model casing. Harmonic motions sweep can accurately confirm the natural frequency of the soil container. In order to prevent any adverse effect of damage accumulation on the test results, the sweep motion tests of white noise and Harmonic motions have been conducted with $0.05 \mathrm{~g}$ peak acceleration. The results of the tests are as follows. The natural frequency of the empty soil container in the $X$ direction is $35.31 \mathrm{~Hz}$. However, the natural frequency of the clay soil in the model in the $X$ direction is $4.62 \mathrm{~Hz}$. This is an indication that the shear stiffness of the soil container is much higher than that of the clay in the model, which can prevent the resonance effect between the soil container and the clay with the ground motion excitation.

Two real earthquake records from the Kobe earthquake measured in 1995 at OKA Station and the Chichi earthquake measured in 1999 at CHK station were used as input motions in the shake table tests, which came from the similar geological conditions of PEER Strong motion Database. Duration and frequency of the earthquake records were scaled for model input motions by a scale factor of 8 , as shown in Figures 6 and 7. The input motions were scaled up to different peak accelerations during the testing program. Four cases of peak acceleration were considered and scaled to $0.05 \mathrm{~g}, 0.1 \mathrm{~g}, 0.2$ and $0.4 \mathrm{~g}$, as tabulated in Table 6 .

\section{Test Results and Discussion}

3.1. Profiles of Maximum Acceleration with Depth. Figure 8 shows the profiles of the maximum horizontal acceleration in the $X$ direction with model tunnel and the surrounding soil for events EQ1, EQ3, EQ5, and EQ7. The profiles of these maximum accelerations from the base of soil container to the surface of the clay (i.e., Sensors A1, A5, A7, and A4). Figure 9 shows the profiles of the maximum horizontal acceleration in the $X$ direction with model tunnel and the surrounding soil for events EQ2, EQ4, EQ6, and EQ8. It can be seen that the maximum acceleration increases gradually from the shake table to the surface of the model clay in "free field" vertical array. However, the maximum acceleration of model tunnel firstly decreases from the shake table to the 


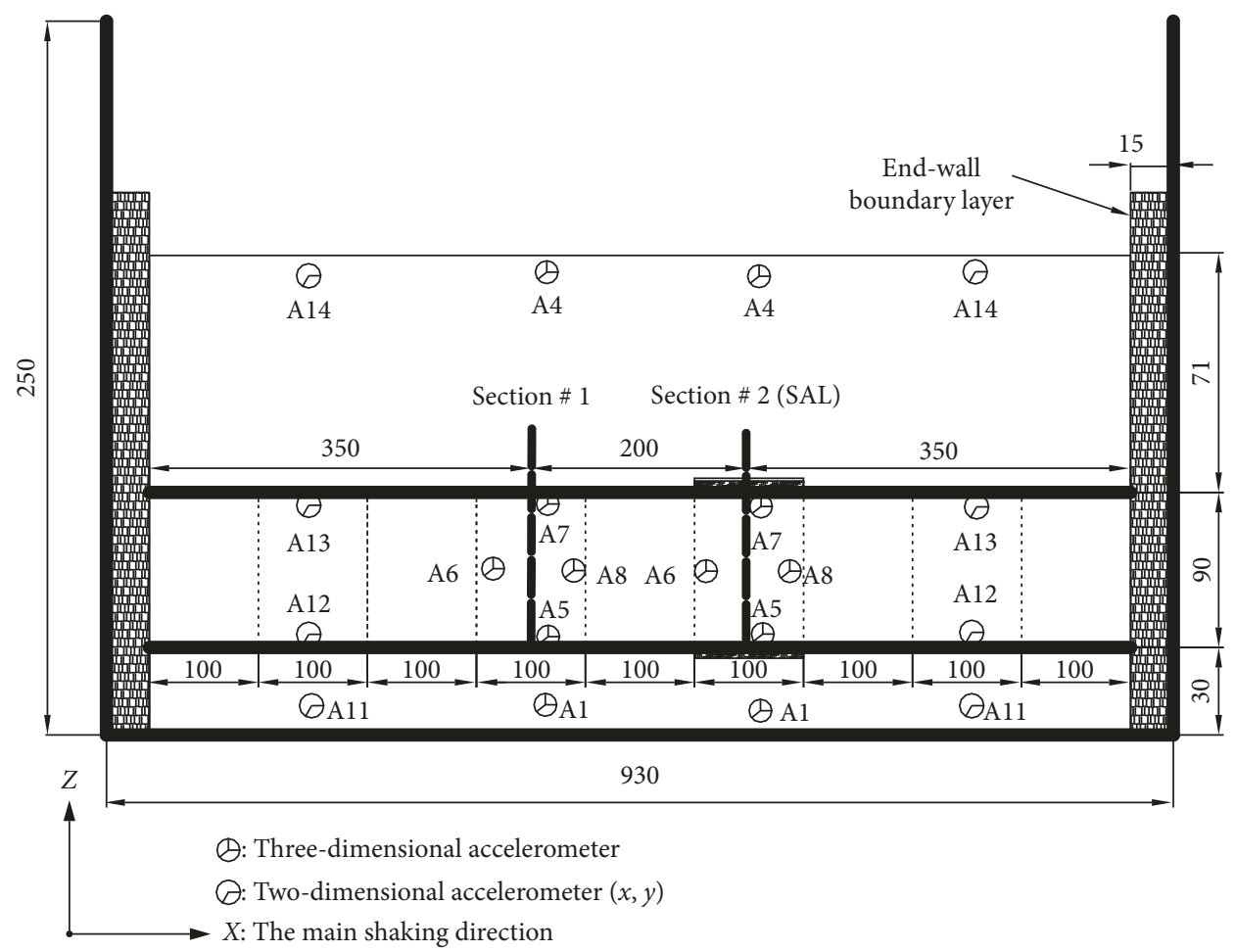

(a)
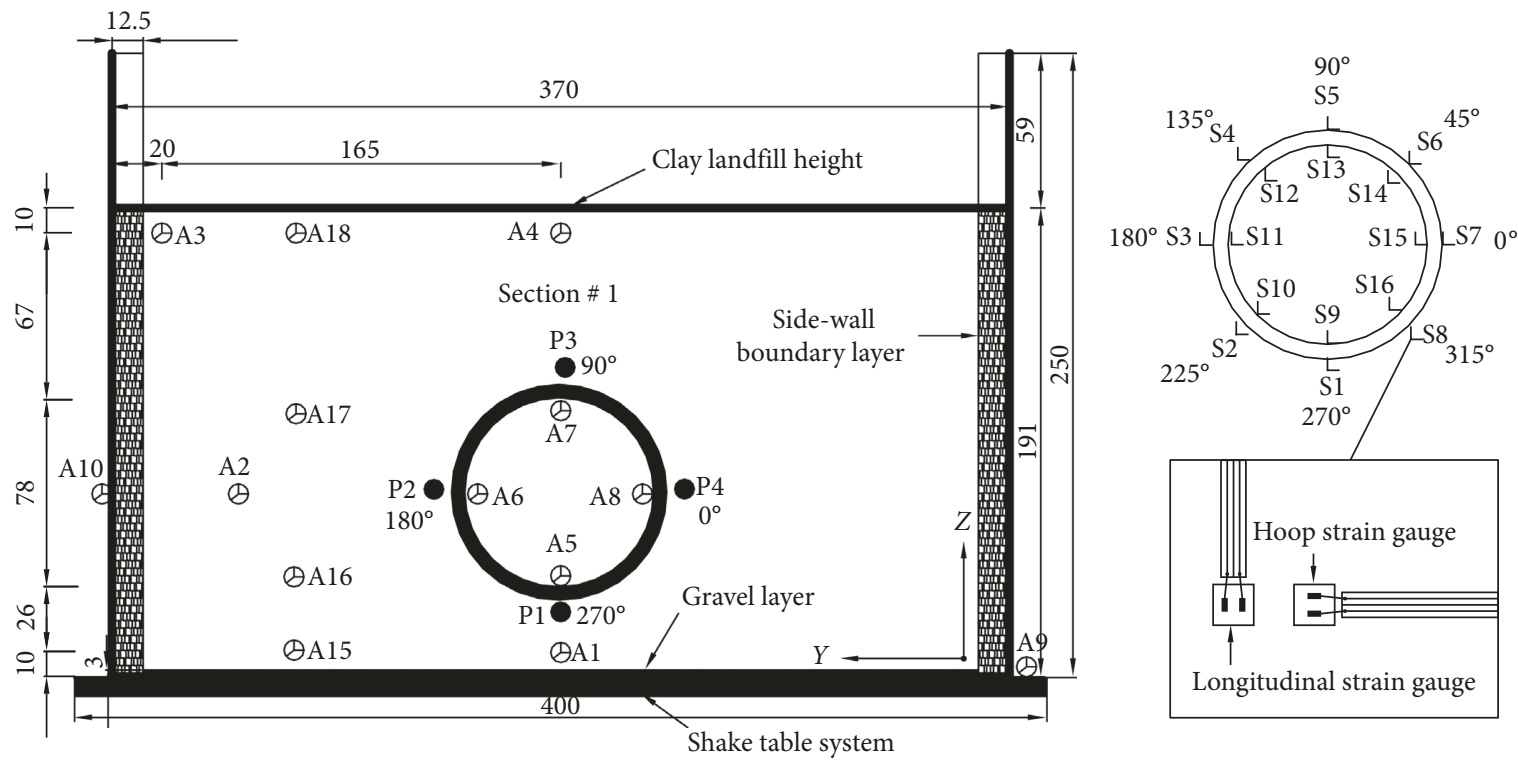

: Soil pressure cell

$\oslash$ : Three-dimensional accelerometer

(b)

Figure 5: Continued. 

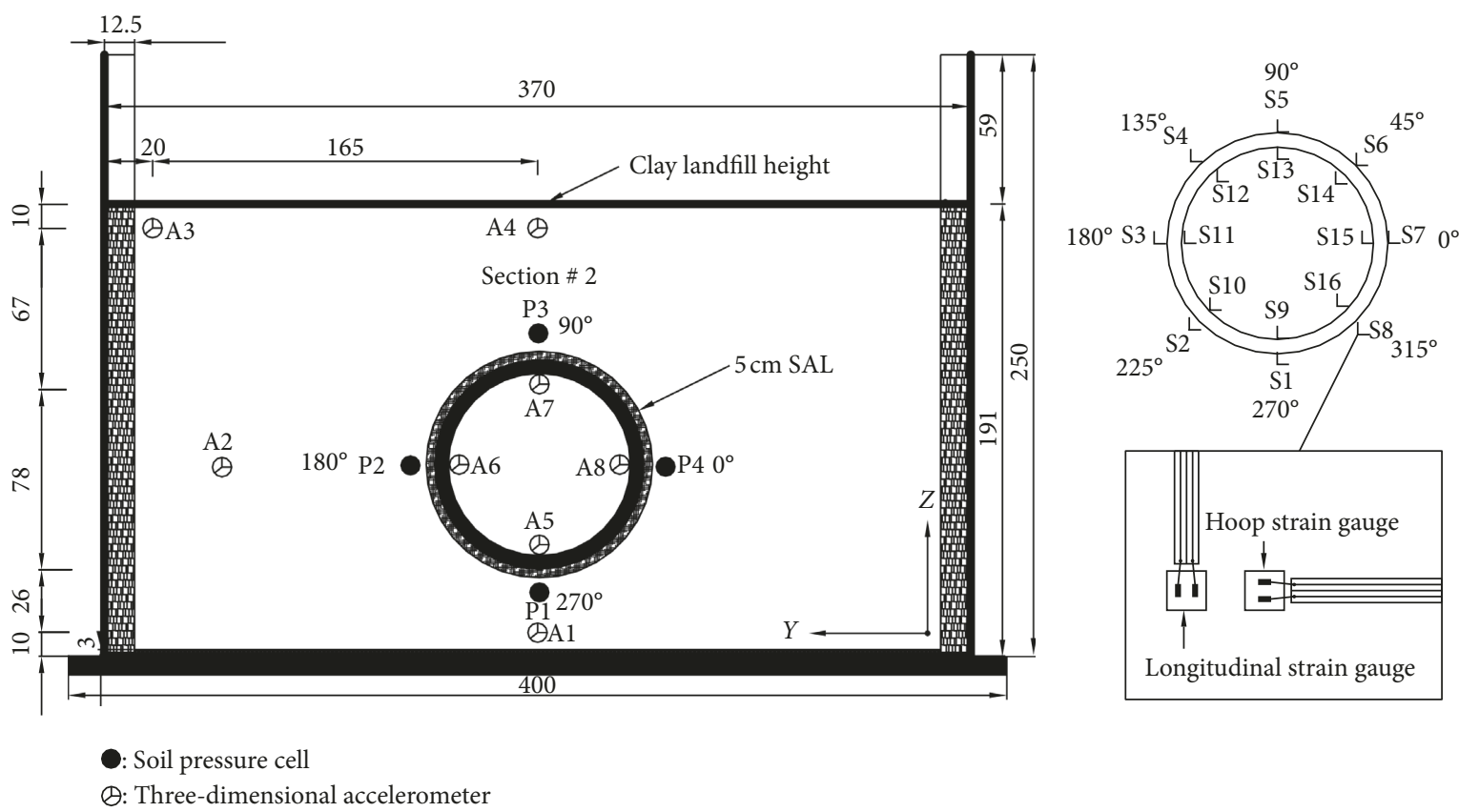

(A): Three-dimensional accelerometer

(c)

Figure 5: Instrumentation layout. (a) Profile layout. (b) Cross section \# 1 layout of sensors. (c) Cross section \# 2 layout of sensors (unit: $\mathrm{cm}$ ).
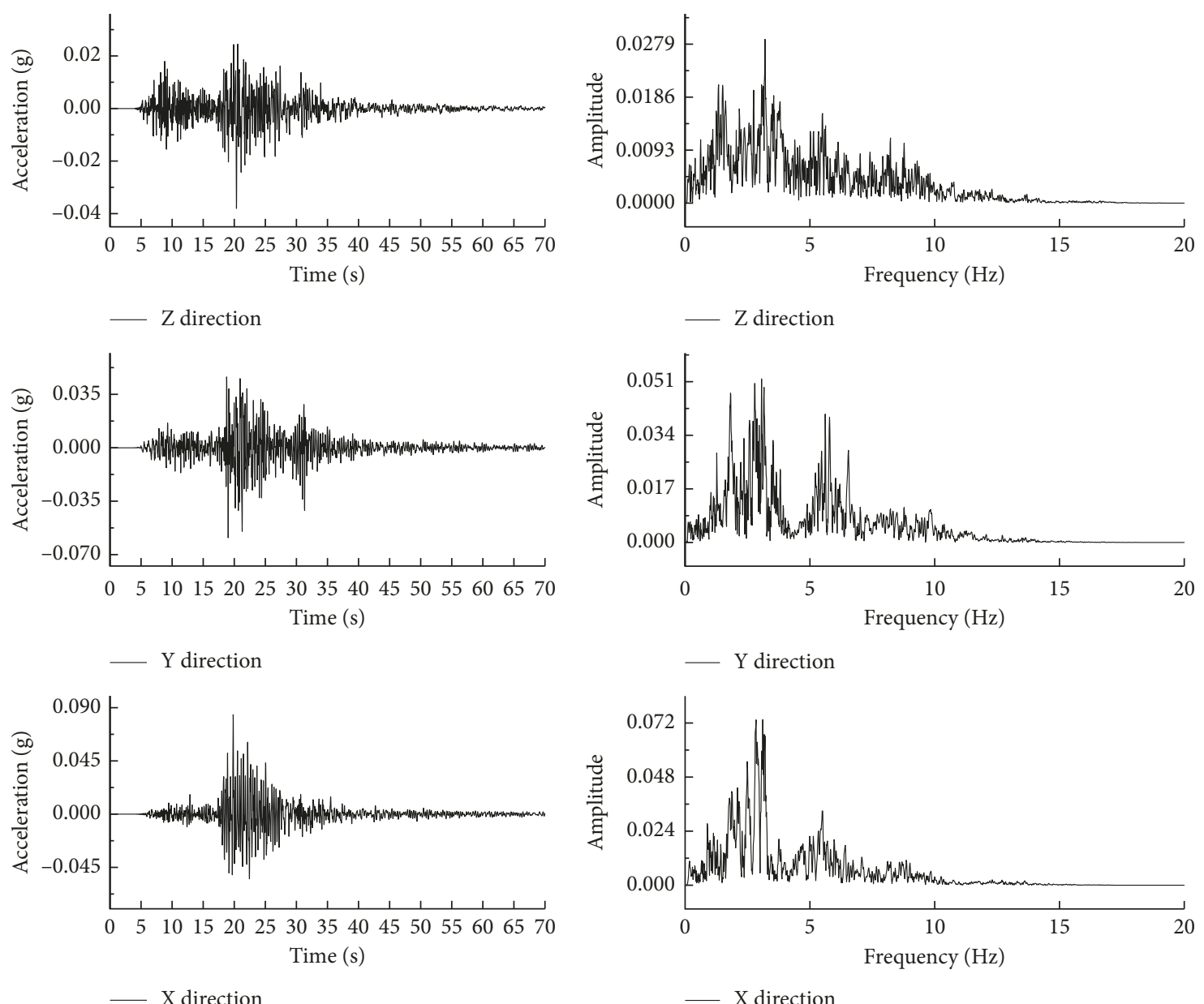

(a)

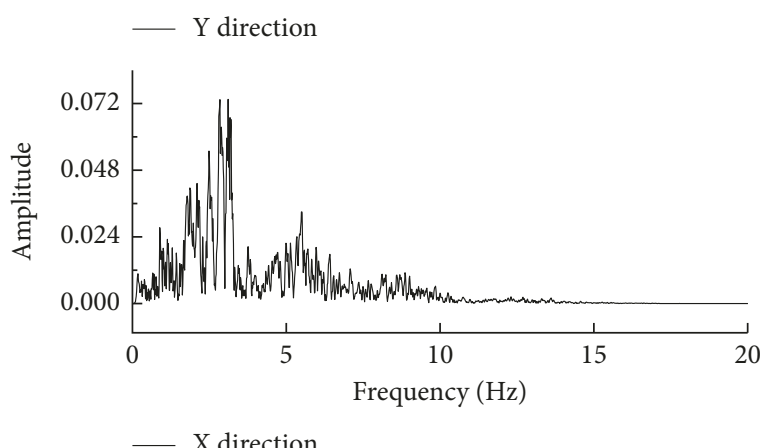

(b)

Figure 6: Acceleration time history and Fourier spectrum of records Kobe motions. 

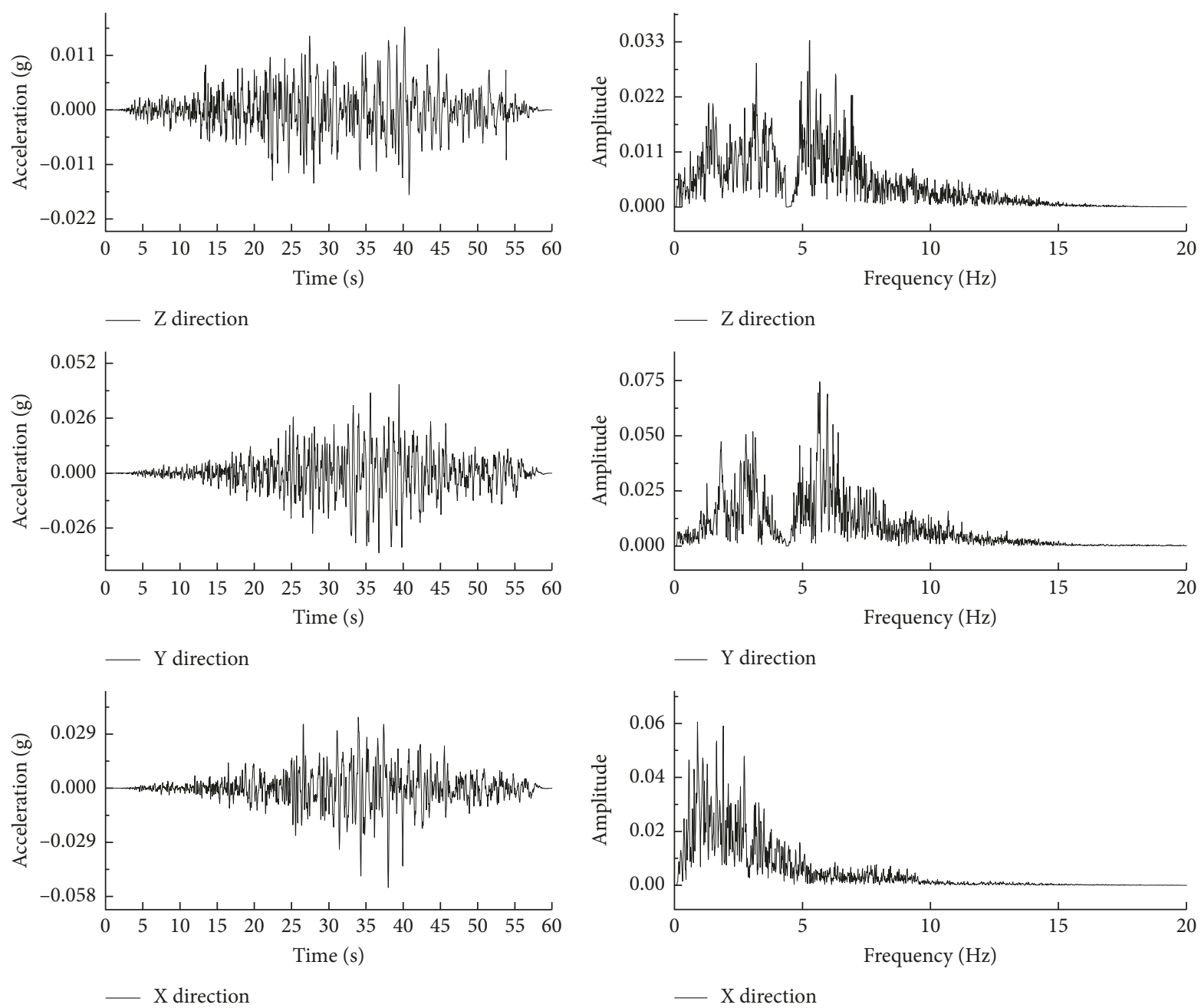

(a)

(b)

Figure 7: Acceleration time history and Fourier spectrum of records Chichi motions.

TABLE 6: Input motion characteristics.

\begin{tabular}{lccccc}
\hline Number & Dimension & $\begin{array}{c}\text { Type of } \\
\text { seismic } \\
\text { motion }\end{array}$ & \multicolumn{3}{c}{ Peak acceleration (g) } \\
& & Kobe & 0.05 & 0.0425 & $Z$ \\
\hline EQ1 & & Chichi & 0.05 & 0.0425 & 0.0325 \\
EQ2 & Kobe & 0.1 & 0.085 & 0.065 \\
EQ3 & Three- & Chichi & 0.1 & 0.085 & 0.065 \\
EQ4 & dimensional & Kobe & 0.2 & 0.17 & 0.13 \\
EQ5 & & Chichi & 0.2 & 0.17 & 0.13 \\
EQ6 & & Kobe & 0.4 & 0.36 & 0.26 \\
EQ7 & & Chichi & 0.4 & 0.36 & 0.26 \\
EQ8 & & & & & \\
\hline
\end{tabular}

base of soil container; the reason is that the weight of the model tunnel is more than $300 \mathrm{~kg}$ and it influences the clay motion below the bottom of model tunnel, and then, these accelerations gradually increase from the bottom of model tunnel to surface of the clay in the model tunnel array. Then, a remarkable increase in acceleration takes place from the



FIgURE 8: Profiles of maximum acceleration with Kobe excitation. 


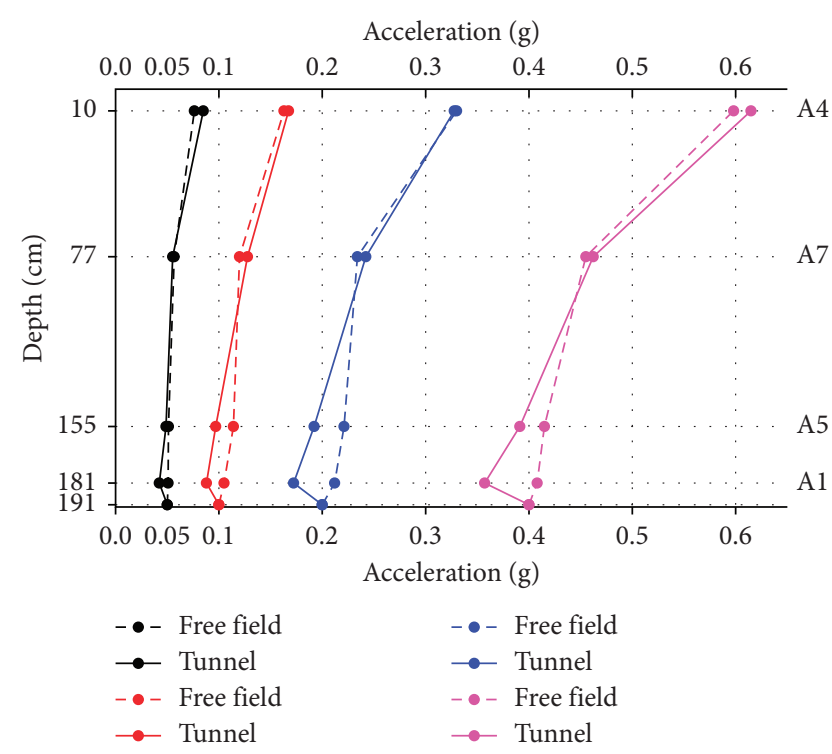

FIGURE 9: Profiles of maximum acceleration with Chichi excitation.

bottom to the crown of model tunnel compared to the same depth "free field," which mainly attributes to the damping of wave propagation in the macroconcrete is lower than the clay soil.

Due to space limitations, only the results for excitation of EQ1, EQ3, EQ5, and EQ7 are summarized in Figure 10, where they are plotted in terms of the ratio between the peak accelerations measured by from the base to the surface of clay for vertical array of the tunnel and the surrounding soil. This ratio is the conventional amplification factor and can be used to investigate the influence of the tunnel on the vertical propagation of shear motions. The amplification factor at the base of clay (A1) in tunnel vertical array is lower than unity for all earthquakes, compared with same position (A15) in free field vertical array, which was attributed to the influence of large-scale model tunnel. The amplification factor at the bottom of model tunnel also is lower than unity, while the amplification factor at the crown of model tunnel (A7) is larger than the same position (A17) in the surrounding soil. This could be an explanation for the nonuniformity behavior of the clay, which is due to the arching effects, as well as the influence of the cavity boundary, reflecting down some of the shear waves propagating upward.

3.2. Effect of SAL on Tunnel Acceleration. Figures 11 and 12 show a comparison between acceleration time history and corresponding spectrum of with SAL and without tests for the bottom (A5) and crown (A7) of the model tunnel subjected to the Kobe with peak acceleration levels $(0.05 \mathrm{~g}$, $0.1 \mathrm{~g}, 0.2 \mathrm{~g}$, and $0.4 \mathrm{~g}$ ), respectively. With the different peak acceleration levels excitation, the maximum accelerations and the maximum amplitude of frequency with the SAL are still lower than those of the model tunnel without SAL, which means that the SAL can reduce the acceleration of the model tunnel. On the other hand, the main frequency of the model tunnel without SAL is the same as the model tunnel with SAL and the difference is the size of the amplitude of

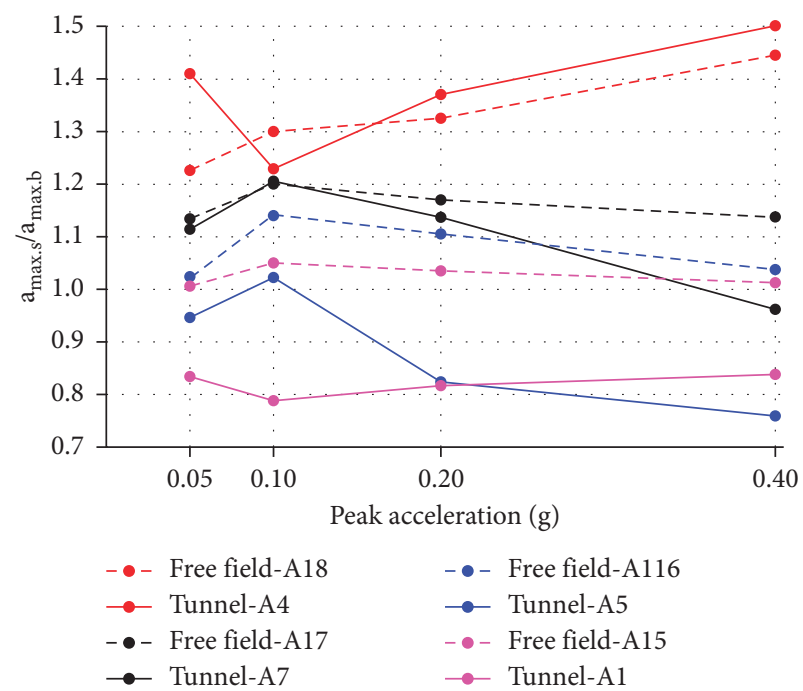

Figure 10: Amplification factor of the acceleration.

frequency, which means that the SAL cannot change the dominant frequency of ground motion.

Figure 13 shows a comparison of the maximum acceleration development for the tunnel with and without the SAL. These accelerations were recorded using the $X$-direction accelerometers. It can be seen that the maximum acceleration firstly decreases from the shake table to the bottom of model tunnel; then, these accelerations gradually increase from the bottom of model tunnel to ground surface of the clay in the model tunnel array of section \# 2. It is interesting that the point of minimum acceleration is located at the bottom of model tunnel with SAL. Meanwhile, the maximum accelerations at the crown and at the bottom (i.e., location A7 and A5) of the model tunnel with the SAL are generally lower than those of the model tunnel without, as the peak acceleration of input motion increases, this phenomenon becomes more pronounced.

Figure 14 shows the amplification factor of the bottom and crown of the model tunnel with and without SAL. It can be seen that at the bottom (at location A5) and at the crown (at location A7) of the model tunnel, the amplification factor of the model tunnel with the SAL is no more than 0.7; however, the amplification factor of the model tunnel is no less than 0.8 , which means the SAL further reduces the amplification factor of the model tunnel. It can also be seen that there is a tendency for the peak acceleration of the tunnel to attenuate from the bottom to the crown of model tunnel with the SAL. This shows that the foam board has positive effect on the reduction of the acceleration.

Figure 15 shows the reduction factor of the SAL with different peak acceleration of input motions. The calculation of the reduction factor is shown in Equation (1). It can be seen that with small peak accelerations, the reduction factor of the SAL at the bottom of model tunnel is the same as the crown of model tunnel. The reduction factor of the SAL to the bottom and crown of the model tunnel is more than $50 \%$ with the $0.1 \mathrm{~g}$ excitation. However, as the peak accelerations of input motion increase (i.e., $0.2 \mathrm{~g}$ and $0.4 \mathrm{~g}$ ), the reduction factor of the SAL gradually decreases. 


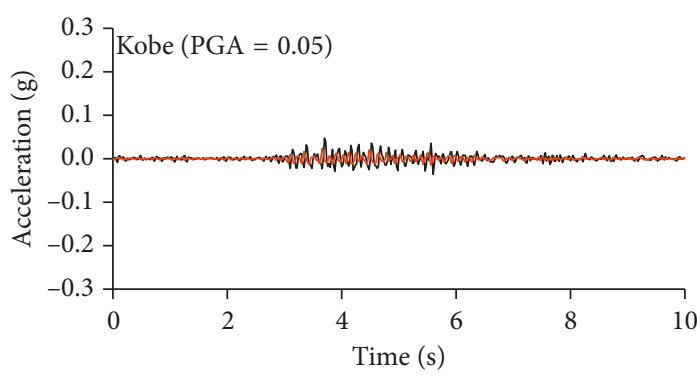

- A5

- A5-SAL

(a)



- A5

- A5-SAL

(c)

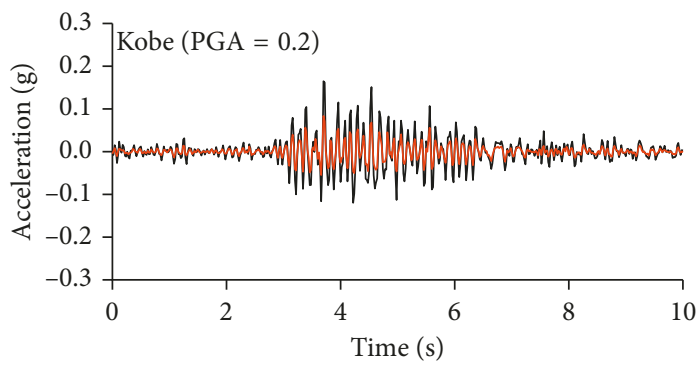

- A5

- A5-SAL

(e)

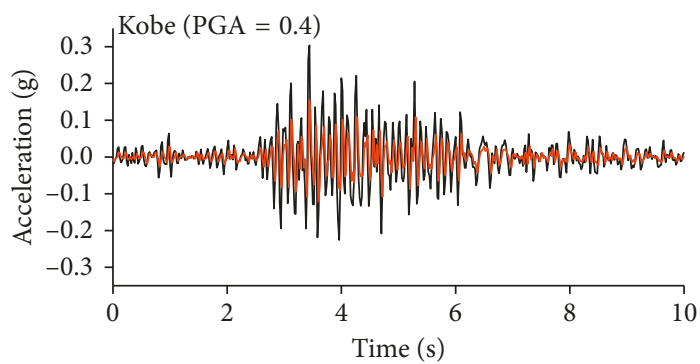

- A5

- A5-SAL

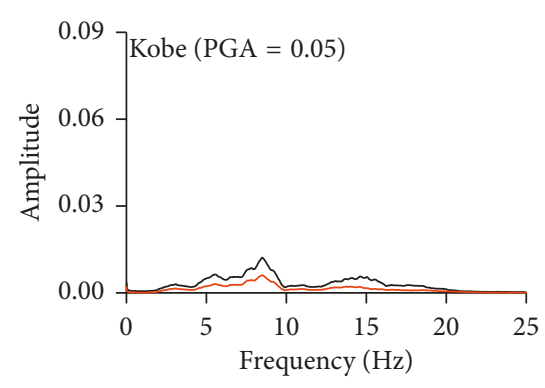

- A5

- A5-SAL

(b)

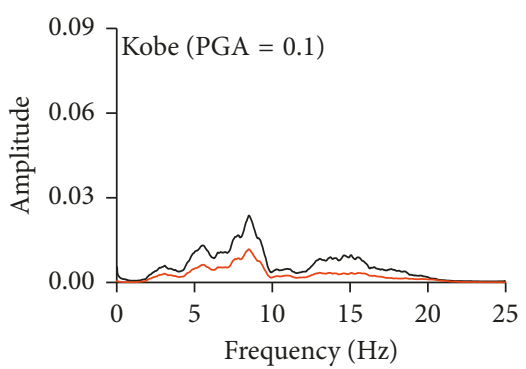

- A5

- A5-SAL

(d)

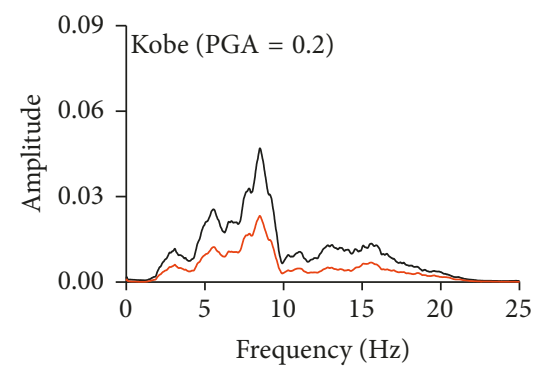

— A5

— A5-SAL

(f)

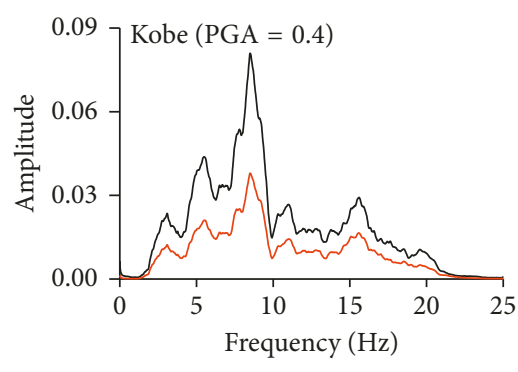

A5

A5-SAL

(h)

(g)

FIgURE 11: Comparison between results acceleration time history and corresponding spectrum of with and without SAL tests for A5 subjected to the Kobe with peak acceleration levels. (a) and (b) Peak acceleration $=0.05$ g. (c) and (d) Peak acceleration $=0.1 \mathrm{~g}$. (e) and (f) Peak acceleration $=0.2 \mathrm{~g}$. $(\mathrm{g})$ and $(\mathrm{h})$ Peak acceleration $=0.4 \mathrm{~g}$. 


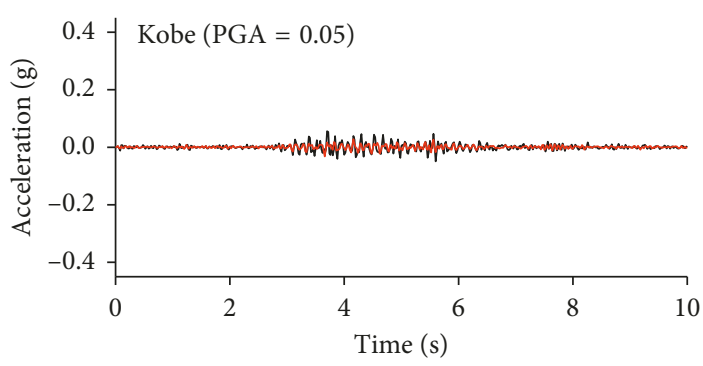

- A7

A7-SAL

(a)

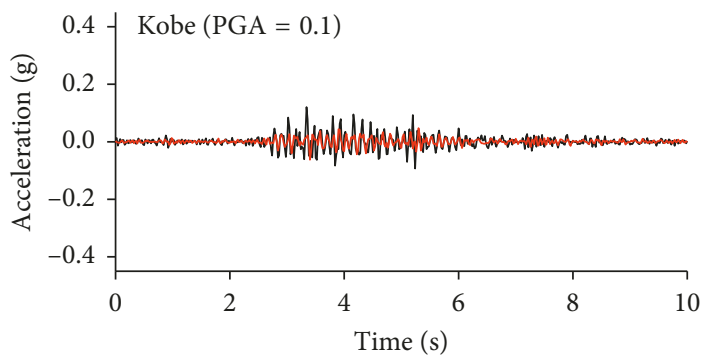

- A7

- A7-SAL

(c)

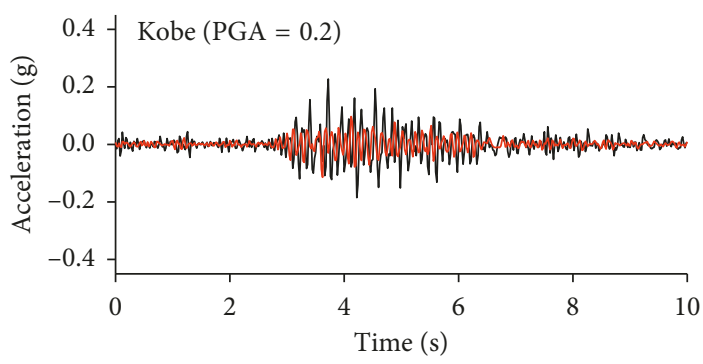

- A7

A7-SAL

(e)

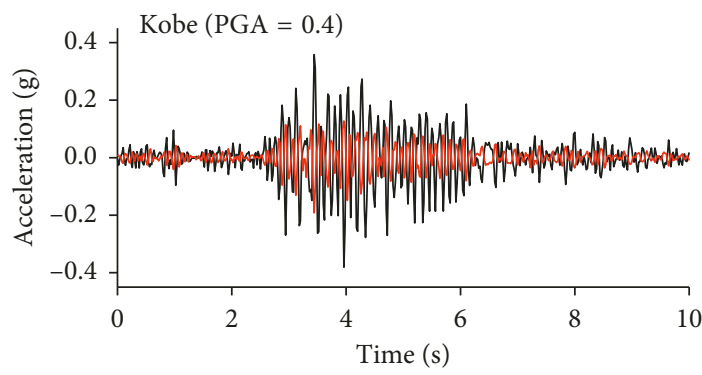

A7

A7-SAL

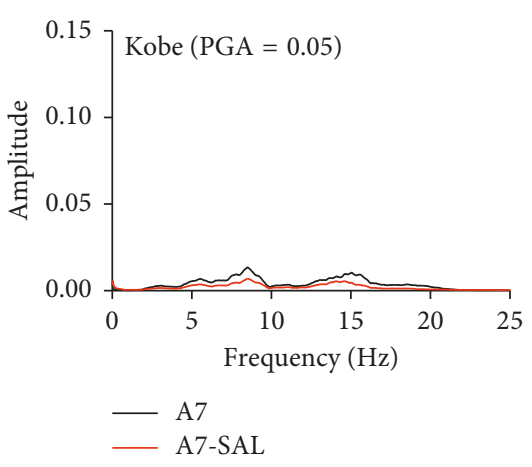

(b)

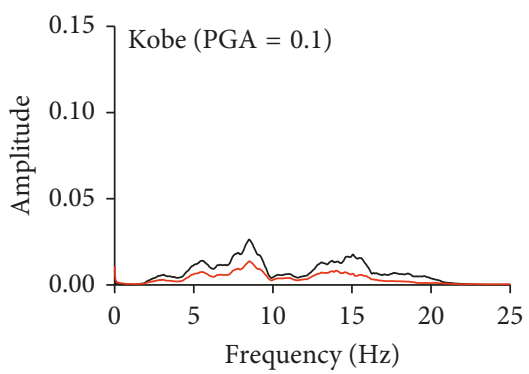

- A7

- A7-SAL

(d)



(f)

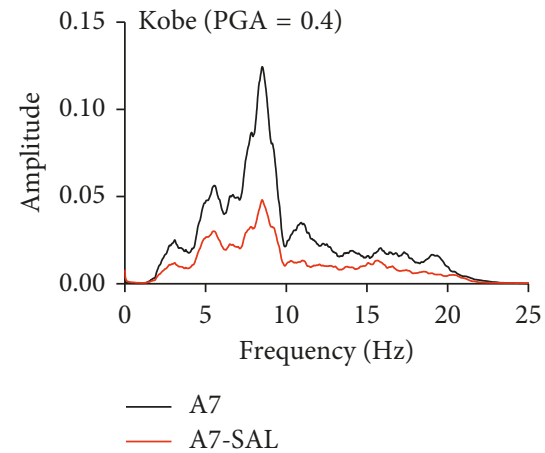

(h)

Figure 12: Comparison between results acceleration time history and corresponding spectrum of with and without SAL tests for A7 subjected to the Kobe with peak acceleration levels. (a) and (b) Peak acceleration $=0.05$ g. (c) and (d) Peak acceleration $=0.1$ g. (e) and (f) Peak acceleration $=0.2 \mathrm{~g}$. $(\mathrm{g})$ and $(\mathrm{h})$ Peak acceleration $=0.4 \mathrm{~g}$. 


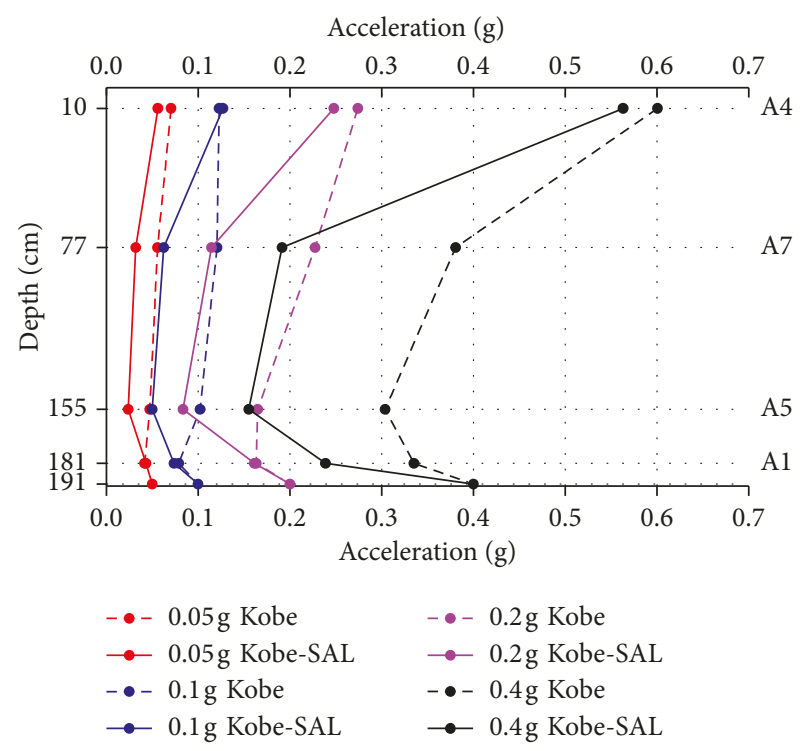

FIGURE 13: Comparison of profiles of max Kobe acceleration with SAL and without tests.

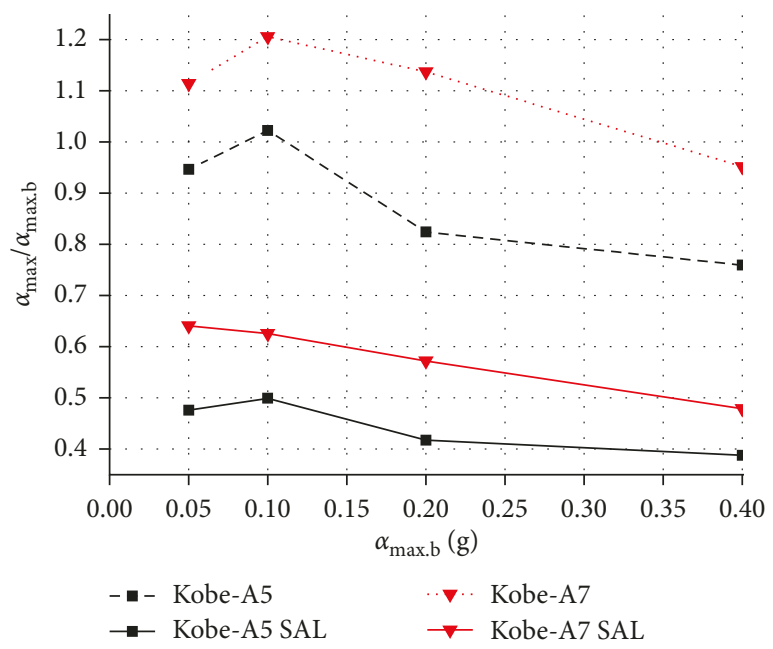

Figure 14: Comparison of amplification factor.

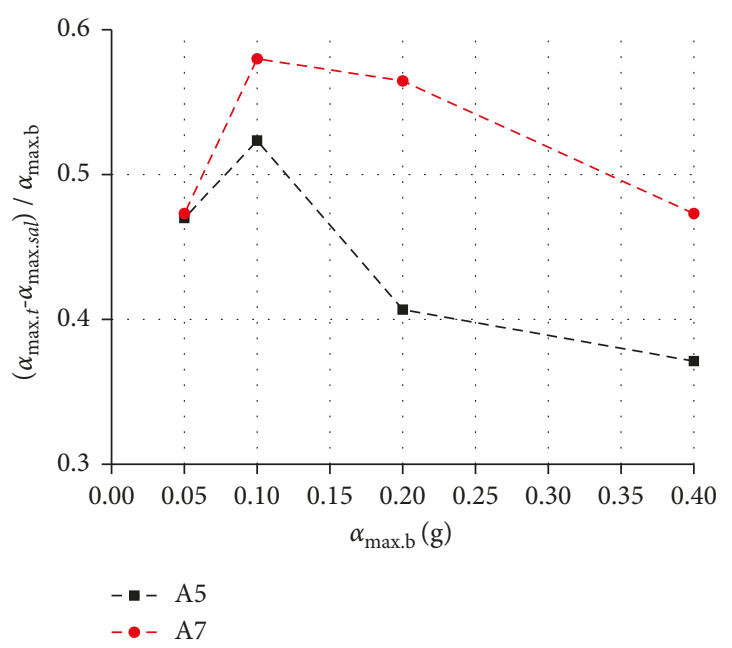

FIgURE 15: The SAL reduction factor.

$$
\text { Reduction factor }=\frac{\left(a_{\max . \mathrm{t}}-a_{\max . \mathrm{sal}}\right)}{a_{\max . \mathrm{b}}},
$$

where, $\alpha_{\max }$ is the maximum acceleration of model tunnel with SAL and without; $\alpha_{\text {max.t }}$ is the maximum acceleration of model tunnel without SAL; $\alpha_{\text {max.sal }}$ is the maximum acceleration of model tunnel with SAL; and $\alpha_{\max . b}$ is the maximum acceleration of shaking table.

3.3. Tunnel Deformation. Because of the variation of soil deformation over the depth, the deformation of the cross section of the tunnel also changes (as shown in Figure 16).

Figure 17 shows the maximum longitudinal and hoop strains at the inner and outer surfaces of the tunnel under excitation in the $X$ direction (i.e., for events EQ1, EQ3, EQ5, and EQ7).

Figure 18 shows the maximum longitudinal and hoop strains at the inner and outer surfaces of the tunnel under excitation in the $X$ direction (i.e., for events EQ2, EQ4, EQ6, and EQ8). The deformation characteristics of the model tunnel are described using the absolute maximum strain in the longitudinal and hoop direction. A positive strain value indicates a "tension" state of model tunnel, and a negative strain value indicates a "compression" state of model tunnel.

Figures $17(a)-17$ (c) show the longitudinal strain at the outer and inner surfaces the model tunnel with the Kobe motions excitation, respectively. It can be seen that at the small peak acceleration $(0.05 \mathrm{~g})$, the longitudinal strain of the model tunnel is in tension and no more than $5 \mu \varepsilon$. As the peak acceleration of input motion increases, the tension strain gradually increases, the maximum tension strain of inner and outer surface of the model tunnel are located at the $0^{\circ}$ and $270^{\circ}$ of the model tunnel, respectively. Figures 18(a)-18(c) also show the longitudinal strain at the outer and inner surfaces the model tunnel with the Chichi waves excitation, respectively. It reveals that at the small peak acceleration $(0.05 \mathrm{~g})$, the longitudinal strain of the model tunnel is in tension and no more than $10 \mu \varepsilon$. As the peak acceleration of input motion increases, the tension strain gradually increases, the maximum tension strain of inner and outer surfaces of the model tunnel are located at the $315^{\circ}$ and $270^{\circ}$ of the model tunnel, respectively. During the tests, the longitudinal strain of the model tunnel along the $X$ direction is in tension with the different seismic motions, and the maximum longitudinal strain is no more than $50 \mu \varepsilon$. Figures $17(\mathrm{~b})-17(\mathrm{~d})$ show the hoop strain of the outer and inner surface of the model tunnel with different peak acceleration Kobe motions. Under the EQ1 excitation, the hoop strain of the model tunnel is in tension and no more than $10 \mu \varepsilon$. With the increasing of input motions, the maximum hoop strain of the outer and inner surface is located at $225^{\circ}$ of the model tunnel. The value of maximum hoop strain of the inner and outer surface is $39.12 \mu \varepsilon$ and $49.56 \mu \varepsilon$, respectively. Figures $18(\mathrm{~b})-18(\mathrm{~d})$ also show the hoop strain of the outer and inner surfaces of the model tunnel with different peak acceleration Chichi motions. Under the EQ2 excitation, the hoop strain of the model tunnel is in tension and no more than $10 \mu \varepsilon$. With the 




Figure 16: Mechanism of the SAL.

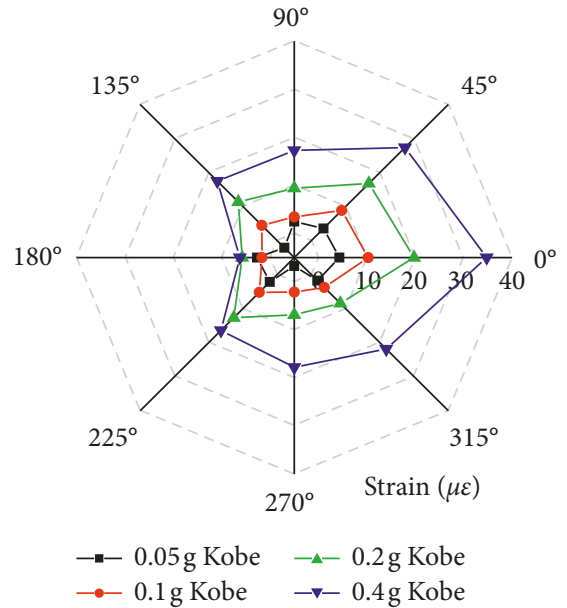

(a)

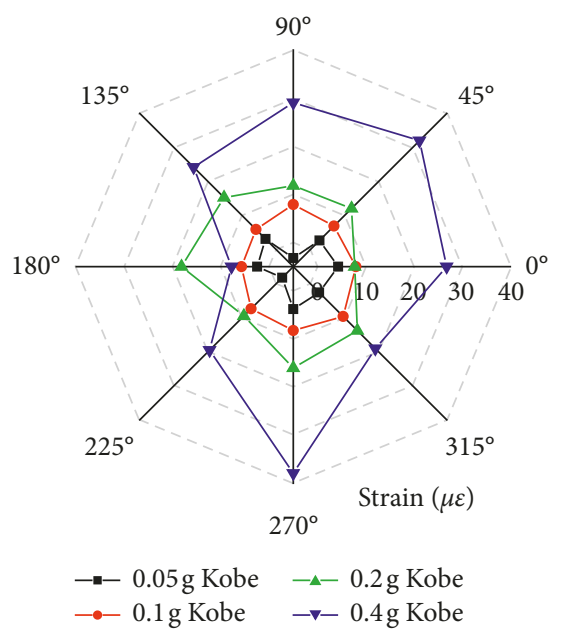

(c)

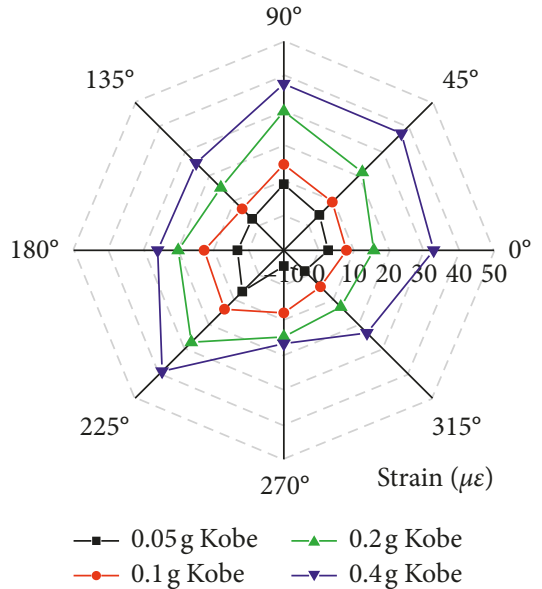

(b)

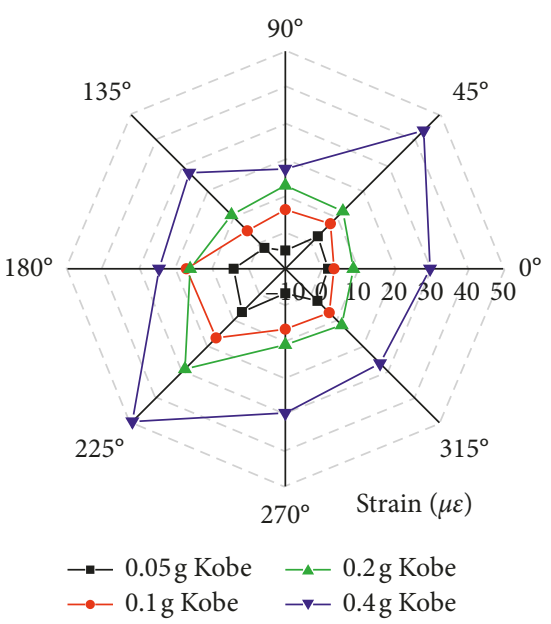

(d)

Figure 17: Maximum strains of the model tunnel subjected to different peak acceleration Kobe motions. (a) Inner surface of the tunnel longitudinal. (b) Inner surface of the tunnel hoop. (c) Outer surface of the tunnel longitudinal. (d) Outer surface of the tunnel hoop.

increasing of input motions, the maximum hoop strain of the inner and outer surface are located at $45^{\circ}$ and $315^{\circ}$ of the model tunnel, respectively. The value of maximum hoop strain of the inner and outer surface is $57.11 \mu \varepsilon$ and $37.93 \mu \varepsilon$, respectively. As can be seen, the hoop strain of the model tunnel is in tension, and then, the maximum deformation of the model tunnel is located at the $45^{\circ}$ conjugate angle.

The deformation of the tunnel can be strongly influenced by the ground deformation. Under the ground motion, the 




(a)

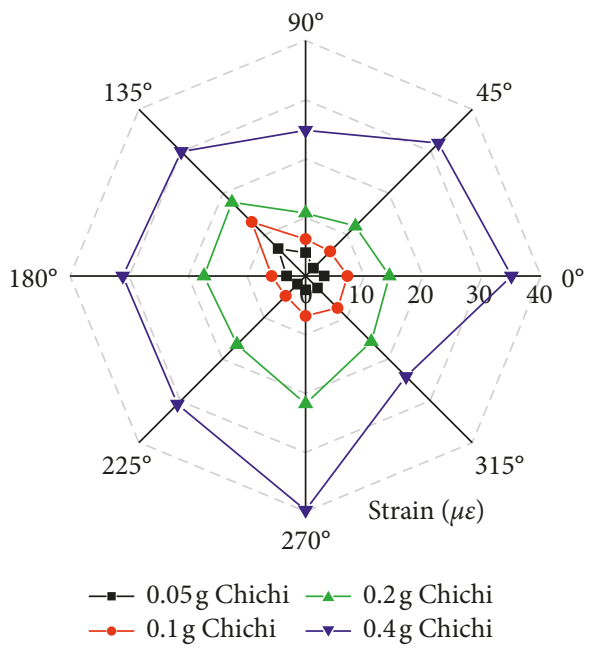

(c)

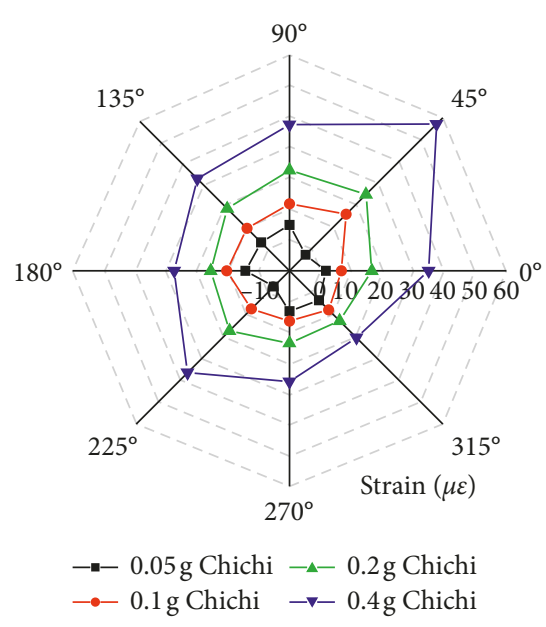

(b)

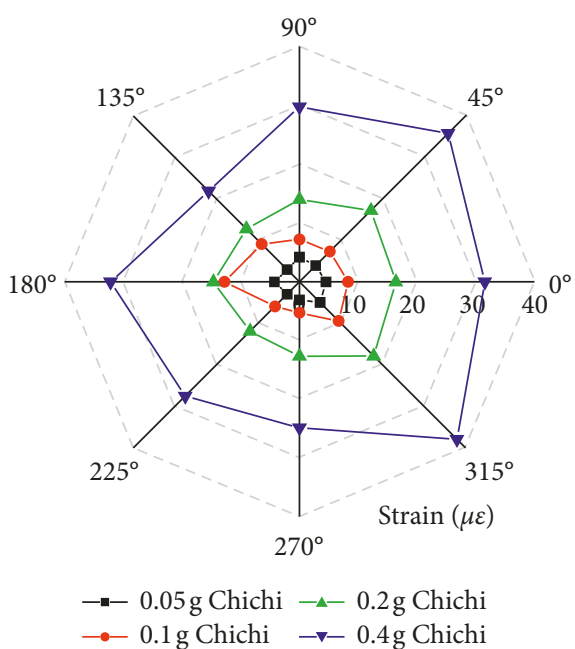

(d)

FiguRE 18: Maximum strains of the model tunnel subjected to different peak acceleration Chichi motions. (a) Inner surface of the tunnel longitudinal. (b) Inner surface of the tunnel hoop. (c) Outer surface of the tunnel longitudinal. (d) Outer surface of the tunnel hoop.

ground deformation developed from underground to the ground surface, as shown in Figure 16. The development of shear strain in the clay due to base excitation caused a shear force at the tunnel.

3.4. Effect of SAL to Concrete Strains. Figure 19 shows the maximum longitudinal and hoop strains at the inner and outer surfaces of the model tunnel with the SAL under excitation for events EQ1, EQ3 EQ5, and EQ7.

Figures 19(a)-19(c) show the longitudinal strain at the outer and inner surface the model tunnel, respectively. It shows that as the peak acceleration of input motion increases, the tension strain gradually increases. However, the maximum tension strain of inner and outer surface of the model tunnel is smaller compared to that of model tunnel without SAL, and the same phenomenon was observed in the Figures 19(b)-19(d).

The maximum strain of the model tunnel with SAL and without is summarized in Table 7. In view of difference of the strain of the model tunnel, the reduction factor of the SAL to the strain of model tunnel was shown by the ratios of the difference between the strain of model tunnel and the strain of the model tunnel with SAL. The longitudinal strain of the model tunnel for the SAL can reduce more than $20 \%$ when compared with the model tunnel without SAL; however, the hoop strain of the model tunnel with the SAL can reduce more than $20 \%$.

3.5. Soil-Structure Interaction. In this study, the soilstructure interaction is investigated through the dynamic earth pressure between the model tunnel and the clay. The dynamic earth pressure cells have measured the dynamic earth pressures at four symmetrical points of the model tunnel (Figure 5(b)). Figure 20 shows the maximum dynamic earth pressures for different peak acceleration levels $(0.05 \mathrm{~g}, 0.1 \mathrm{~g}, 0.2 \mathrm{~g}$, and $0.4 \mathrm{~g})$. It can be seen that the maximum earth pressure took place at the bottom of the model tunnel and the reason is the weight of model tunnel 


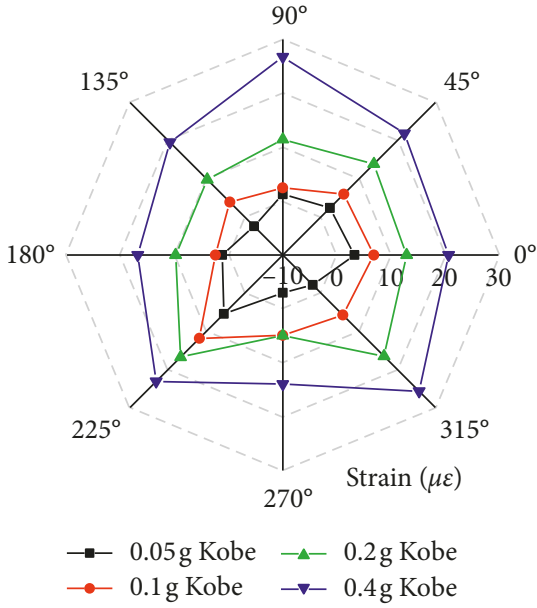

(a)

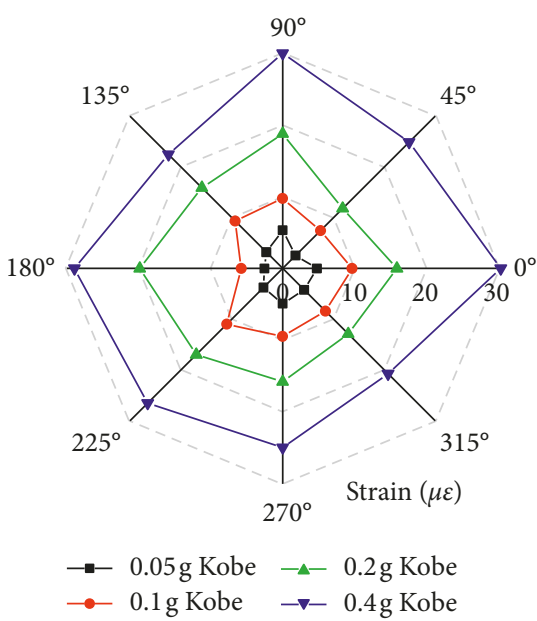

(c)

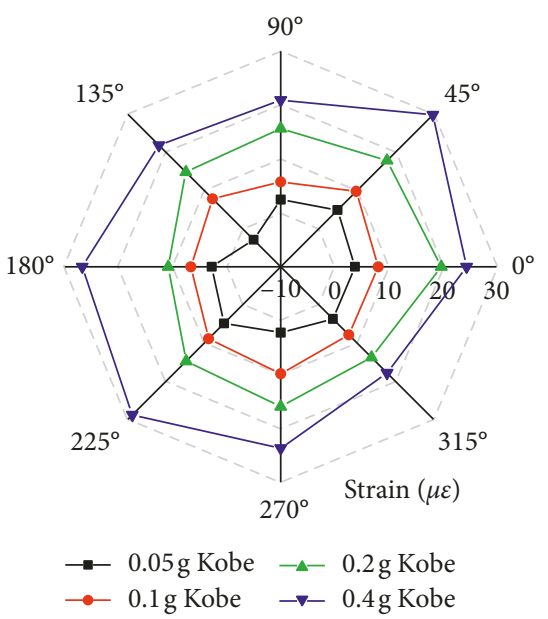

(b)

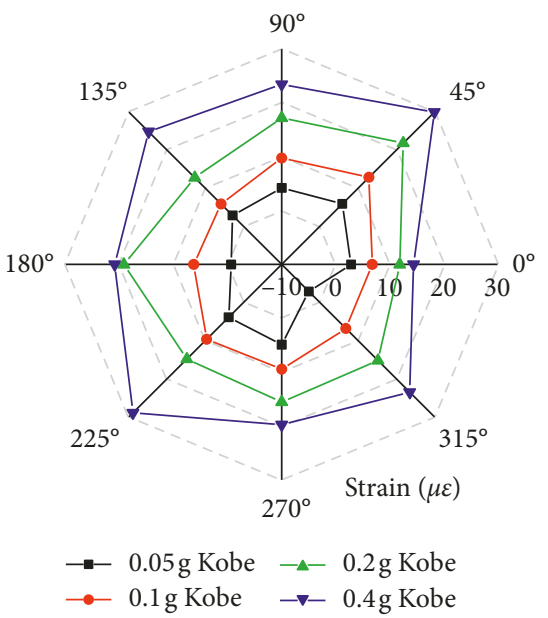

(d)

FIGURE 19: Maximum strains of the model tunnel with SAL for different peak acceleration levels. (a) Inner surface of the tunnel longitudinal. (b) Inner surface of the tunnel hoop. (c) Outer surface of the tunnel longitudinal. (d) Outer surface of the tunnel hoop.

TABLE 7: The maximum strain of the model tunnel with SAL and without.

\begin{tabular}{|c|c|c|c|c|}
\hline Maximum str & & Model tunnel & Model tunnel with SAL & Reduction factor $=\left(S_{\mathrm{T}}-S_{\mathrm{SAL}}\right) / S_{\mathrm{T}}(\%)$ \\
\hline & Inner surface & 34.76 & 26.76 & 23.01 \\
\hline Longitudinal & Outer surface & 37.76 & 29.97 & 20.63 \\
\hline Hoop & Inner surface & 37.45 & 29.89 & 20.18 \\
\hline HоOр & Outer surface & 49.56 & 28.98 & 41.52 \\
\hline
\end{tabular}

$S_{\mathrm{SAL}}$ is the strain of the model tunnel with SAL and $S_{\mathrm{T}}$ is the strain of the model tunnel.

is about $300 \mathrm{~kg}$, and the earth pressure at the bottom of the model tunnel is caused by the inertia of model tunnel weight and clay-model tunnel interaction with excitation of ground motion. The earth pressures at the crown of model tunnel are higher than those on the side of model tunnel.

3.6. Effect of the SAL to Soil-Structure Interaction. Figure 21 shows a comparison of the maximum dynamic earth pressures of the model tunnel with and without the SAL under the excitation of E1, EQ3, EQ5, and EQ7. The earth pressures of the tunnel with the SAL were lower than those of the tunnel without SAL. Figure 22 shows the reduction factor of the SAL to the dynamic earth pressure subjected to different peak acceleration levels. The calculation of the reduction factor is shown in Equation (2). It can be seen that the reduction factor of the SAL firstly decreases from $0.05 \mathrm{~g}$ to $0.1 \mathrm{~g}$ of input motions; then, with the increase of the input motions, the reduction factor of the SAL also increases. The SAL can reduce $10 \%-50 \%$ dynamic earth pressure the of the tunnel model without SAL. The reduction factor of the SAL to earth pressure is minimum when the peak acceleration is $0.1 \mathrm{~g}$. 


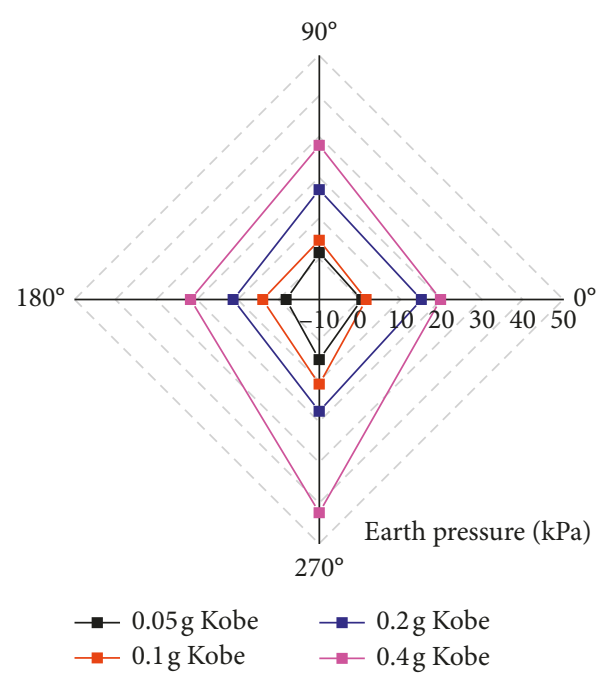

(a)



(b)

FIgURE 20: Maximum earth pressure distribution on soil-structure interface. (a) The excitation of Kobe motions. (b) The excitation of Chichi motions.

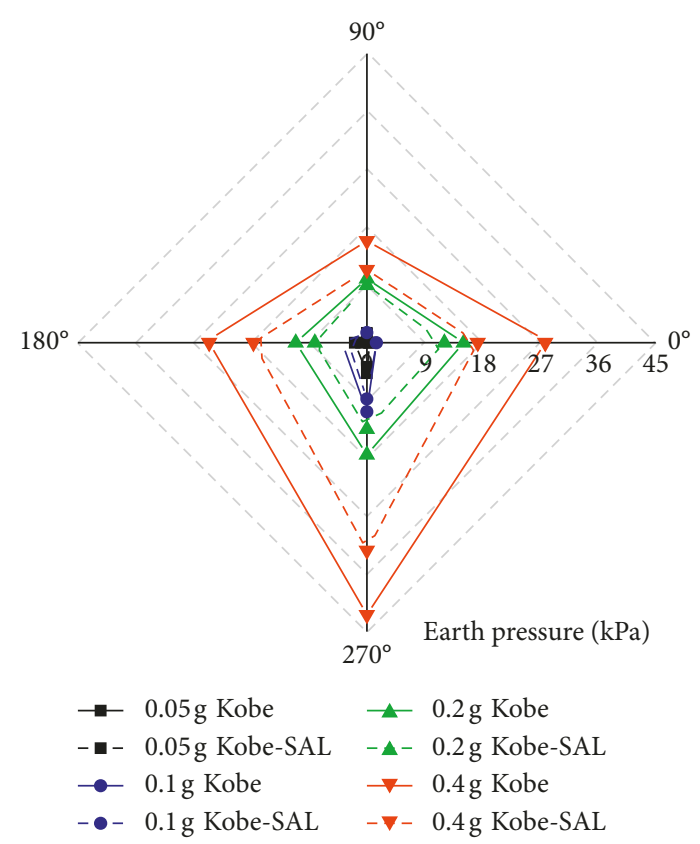

FIgURE 21: Comparison of maximum earth pressure with the SAL.

$$
\text { Reduction factor }=\frac{\left(E_{\max }-E_{\max . s a l}\right)}{E_{\max }},
$$

$E_{\max }$ is the earth pressure of model tunnel without SAL; $E_{\text {max.sal }}$ is the earth pressure of model tunnel with SAL.

\section{Conclusion}

This paper presented experimental results obtained from a series of shake table tests on a circle model tunnel embedded in compacted clay. A soil container filled with clay was used. Using strain gauges, accelerometers,

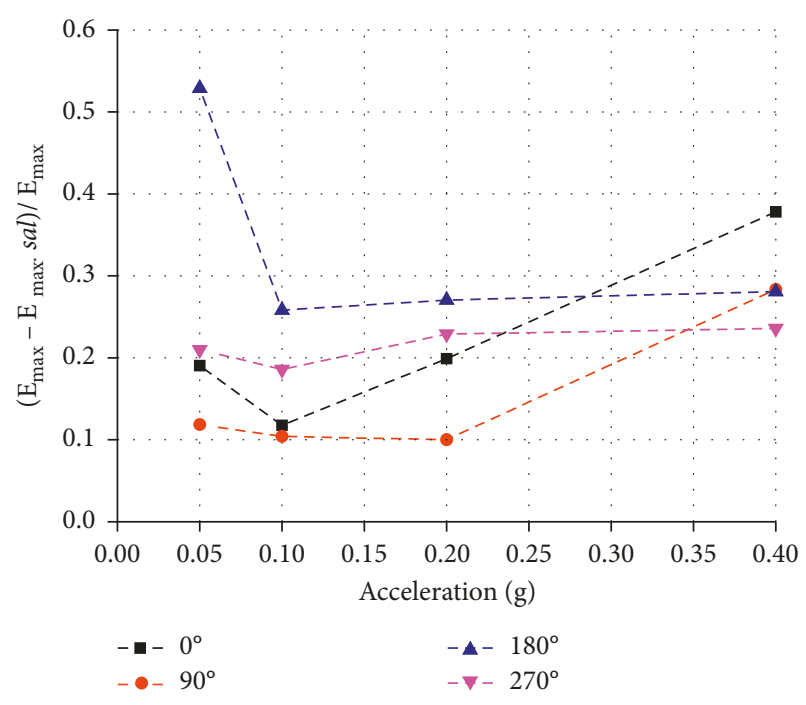

Figure 22: The SAL reduction factor.

and dynamic earth pressure cells, the seismic response of the tunnel during shake table experiment was measured. The dynamic response of the model tunnel with and without the SAL material has also been compared and analyzed. From the results, we can summarize the following:

(i) The peak accelerations of the $X$ direction increase gradually from the shake table to the surface of the model clay in "free field" vertical array; the peak accelerations in the $X$ direction firstly decrease and then increase from the base of soil container to the surface of the model clay. In the model tunnel vertical array, due to the weight of model tunnel and the difference of wave propagation in the macroconcrete and clay. 
(ii) The SAL can reduce the acceleration of model tunnel, and the horizontal acceleration of the model tunnel with SAL in $X$ direction was just $30-60 \%$ of that for tunnel lining without a SAL. The reduction factor of SAL to the acceleration firstly increases; however, with the increasing of peak accelerations, the reduction factor of the SAL decreases instead.

(iii) The deformation characteristic of the model tunnel is mainly in tension, and as the peak accelerations of input motion increase, the tension strain of the model tunnel in longitudinal and hoop direction also increases; however, the maximum tension strain of model tunnel is located at the $45^{\circ}$ conjugate angle due to the shear force of input motion.

(iv) The longitudinal strain of the model tunnel for the SAL can reduce more than $20 \%$ that of the model tunnel without with the main $X$ excitation; however, the hoop strain of the model tunnel with the SAL also can reduce more than $20 \%$ that of the model tunnel without, which means the SAL can effectively reduce the strain of the model tunnel in longitudinal and hoop direction.

(v) The dynamic earth pressures were larger at the bottom of the model tunnel compared to the other position of model tunnel

(vi) The SAL can reduce $10 \%-50 \%$ dynamic earth pressure of the tunnel model without SAL. The reduction factor of the SAL firstly decreases, and then, as the peak accelerations of input motion increase, the reduction factor of the SAL also increases.

\section{Data Availability}

All data generated or analyzed during the study are included in this paper.

\section{Conflicts of Interest}

The authors declare that they have no conflicts of interest regarding the publication of this paper.

\section{Acknowledgments}

This research was supported by the China Railway Corporation Key Project (grant no. 2014G010-G) and National Engineering Laboratory for Construction Technology of High Speed Railway. All supports are gratefully acknowledged.

\section{References}

[1] S. Hassan, K. Alexander, M. A. Youssef, B. Hashash, and J. I.-C. Yao, "Contact interface in seismic analysis of circular tunnels," Tunneling and Underground Space Technology, vol. 24, pp. 482-490, 2009.

[2] A. Giannakou, P. Nomikos, I. Anastasopoulos, A. Sofianos, G. Gazetas, and Y. Mitra, "Seismic behaviour of tunnels in soft soil: parametric numerical study and investigation on the causes of failure of the Bolu Tunnel (Duzce, Turkey, 1999)," in Underground Space Use: Analysis of the Past and Lessons for the Future, Y. Erdem and T. Solak, Eds., Taylor and Francis Group, London, UK, 2005.

[3] Y. S. Shen, B. Gao, X. M. Yang, and S. J. Tao, "Seimic damage mechanism and dynamic deformation characteristic analysis of mountain tunnel after Wenchuan earthquake," Engineering Geology, vol. 180, pp. 85-98, 2014.

[4] J. N. Wang, "Seismic design of tunnels a simple state-of-theart design approach," in Monograph 7, Parsons Brinckerhoff, New York, NY, USA, 1993.

[5] J. Penzien, "Seismically induced racking of tunnel linings," Earthquake Engineering and Structural Dynamics, vol. 29, no. 5, pp. 683-691, 2000.

[6] Y. M. A. Hashash, J. J. Hook, B. Schmidt, and J. I.-C. Yao, "Seismic design and analysis of underground structures," Tunneling and Underground Space Technology, vol. 16, no. 2, pp. 247-293, 2001.

[7] ISO 23469, Bases for Design of Structures - Seismic Actions for Designing Geotechnical Works, ISO International Standard, Geneva, Switzerland, 2005.

[8] FWHA, Technical Manual for Design and Construction of Road Tunnels-Civil elements, US Department of Transportation, Federal Highway Administration, Washington, DC, USA, 2009.

[9] G. Tsinidis, C. Heron, K. Pitilakis, and G. S. P. Madabhushi, "Physical modeling for the evaluation of the seismic behavior of square tunnels," in Geotechnical, Geological and Earthquake Engineering, pp. 389-406, Springer Nature, Basel, Switzerland, 2014.

[10] G. Q. Liu, J. T. Chen, M. Xiao, and Y. Yang, "Dynamic response simulation of lining structure for tunnel portal section under seismic load," Shock and Vibration, vol. 2018, Article ID 7851259, 10 pages, 2018.

[11] Q. X. Yan, H. Chen, W. Y. Chen, J. Zhang, S. Ma, and $\mathrm{X}$. Hua, "Dynamic characteristic and fatigue accumulative damage of a cross shield tunnel structure under vibration load," Shock and Vibration, vol. 2018, Article ID 9525680, 14 pages, 2018.

[12] X. J. Cheng, L. P. Jing, J. Cui, Y. Q. Li, and R. Dong, "Shaking-table tests for immersed tunnels at different sites," Shock and Vibration, vol. 2017, Article ID 2546318, 11 pages, 2018.

[13] C. Ulas, S. P. Gopal, and M. Ushi, "A model study on the effects of input motion on the seismic behaviour of tunnels," Soil Dynamics and Earthquake Engineering, vol. 31, no. 3, pp. 452-462, 2010.

[14] G. Tsinidis, C. Heron, K. Pitilakis, and S. P. G. Madabhushi, "Centrifuge modeling of the dynamic behavior of square tunnels in sand," in Geological and Earthquake Engineering, pp. 509-523, Springer Nature, Basel, Switzerland, 2015.

[15] G. Tsinidis, E. Rovithis, K. Pitilakis, and J. L. Chazelas, "Dynamic response of shallow rectangular tunnels in clay by centrifuge testing," in Experimental Research in Earthquake Engineering - EUSERIES Concluding Workshop, Geotechnical Geological and Earthquake Engineering, F. Taucer and R. Apostolska, Eds., pp. 493-507, Springer, Berlin, Germany, 2015.

[16] L. Jiang, J. Chen, and J. Li, "Seismic response of underground utility tunnels: shaking table testing and FEM analysis," Earthquake Engineering and Engineering Vibration, vol. 9, no. 4, pp. 555-567, 2010.

[17] U. Cilingir and S. P. G. Madabhushi, "Effect of depth on the seismic response of square tunnels," Soils and Foundations, vol. 51, no. 3, pp. 449-457, 2011. 
[18] D. G. Andrew, Physical scale model of geotechnical structure at one-g, Ph.D. Dissertation, California Institute of Technology, Pasadena, CA, USA, 1997.

[19] R. V. Whitman and P. C. Lambe, "Effect of boundary conditions upon centrifuge experiments using ground motion simulation," Geotechnical Testing Journal, vol. 9, no. 2, pp. 61-71, 1986.

[20] K. L. Fishman, J. B. Mander, and R. Richards Jr., "Laboratory study of seismic free-field response of sand," Soil Dynamic Earthquake Engineering, vol. 14, no. 1, pp. 33-43, 1995.

[21] H. Mizuno and M. Iiba, "Shaking table testing of seismic building-pile-soil interaction," in Proceedings of the 8th World Conference on Earthquake Engineering, San Francisco, CA, USA, July 1984.

[22] D. Lombardi, S. Bhattacharya, F. Scarpa, and M. Bianchi, "Dynamic response of a geotechnical rigid model container with absorbing boundaries," Soil Dynamic and Earthquake Engineering, vol. 69, pp. 46-56, 2015.

[23] I. S. Ha, S. M. Olson, M. Seo, and M.-M. Kim, "Evaluation of reliquefaction resistance using shaking table tests," Soil Dynamic Earthquake Engineering, vol. 31, no. 4, pp. 682-691, 2011.

[24] S. Bhattacharya, A. Muralikrishna, D. Lombardi, A. Crewe, and N. Alexander, "Economic MEMS based3-axis water proof accelerometer for dynamic geo-engineering applications," Soil Dynamics and Earthquake Engineering, vol. 36, pp. 111-118, 2012.

[25] M. W. David, C. Adam, and T. Colin, "Shaking table testing of geotechnical models," International Journal of Physical Modelling in Geotechnics, vol. 1, pp. 1-13, 2002.

[26] University of Cambridge, Mitrani HLiquefaction remediation techniques for existing buildings, Ph.D. thesis, University of Cambridge, Cambridge, UK, 2006.

[27] G. Lanzano, E. Bilotta, G. Russo, F. Silvestri, and S. P. Gopal Madabhushi, "Centrifuge modelling of seismic loading on tunnels in sand," Geotechnical Testing Journal, vol. 35, no. 6, article 104348, 2012.

[28] T. Yamada, H. Nagatani, and N. Ohbo, "Seismic performance of flat cross-sectional tunnel with countermeasures," in Proceedings of the 13th World Conference on Earthquake Engineering, Prentice-Hall, Vancouver, BC, Canada, August 2004.

[29] Z. Y. Chen and H. Shen, "Dynamic centrifuge tests on isolation mechanism of tunnels subjected to seismic shaking," Tunnelling and Underground Space Technology, vol. 42, pp. 67-77, 2014.

[30] O. Kusakabe, J. Takemura, A. Takahashi et al., "Physical modeling of seismic responses of underground structures," in Proceedings of Twelth International Conference of International Association for Computer Methods and Advances in Geomechanics, Goa, India, October 2008. 


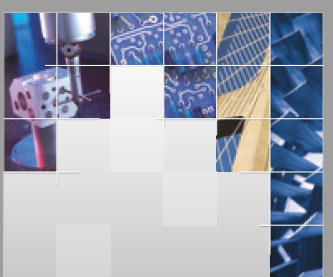

\section{Enfincering}
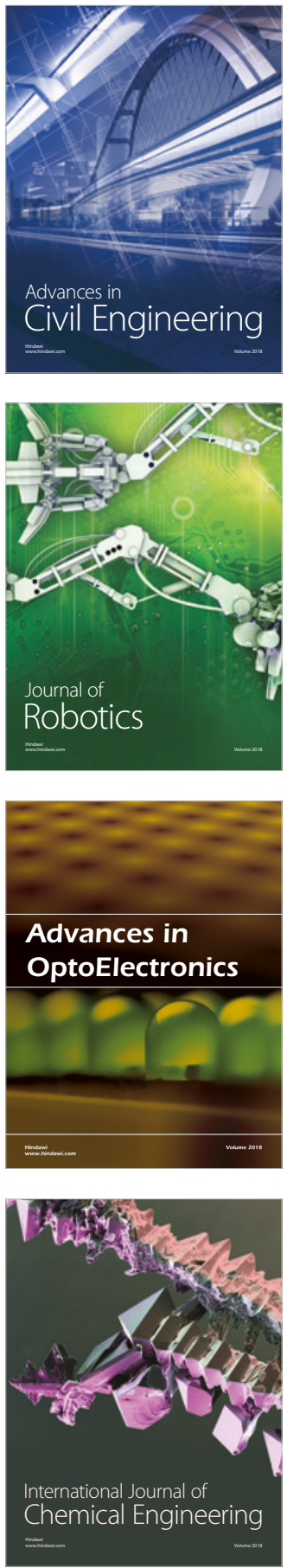

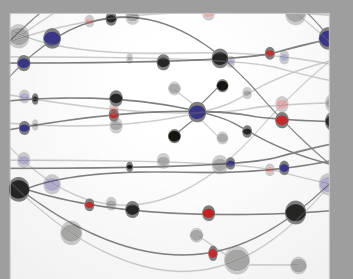

\section{Rotating \\ Machinery}

The Scientific World Journal

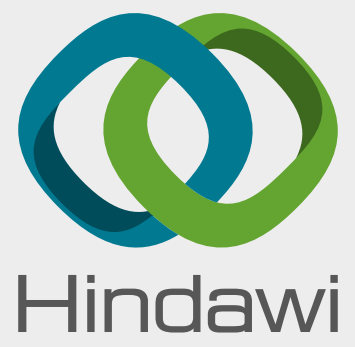

Submit your manuscripts at

www.hindawi.com

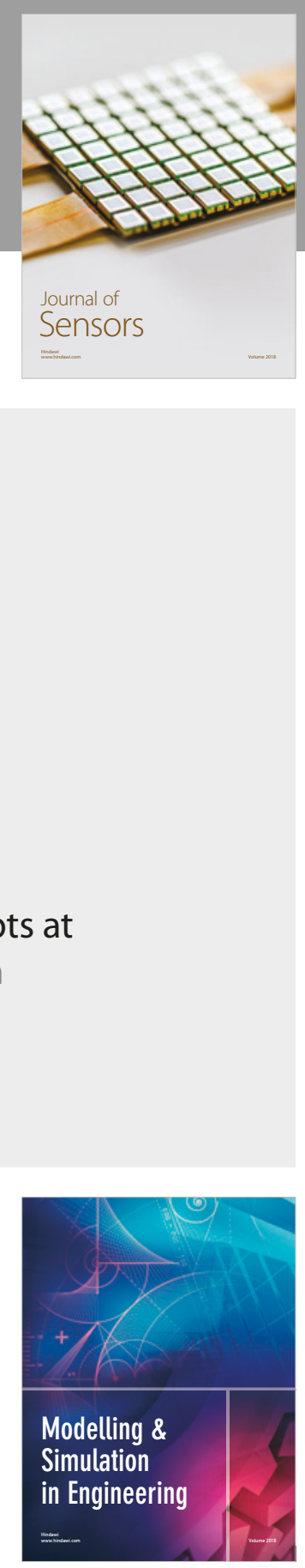

\section{Advances \\ Multimedia}
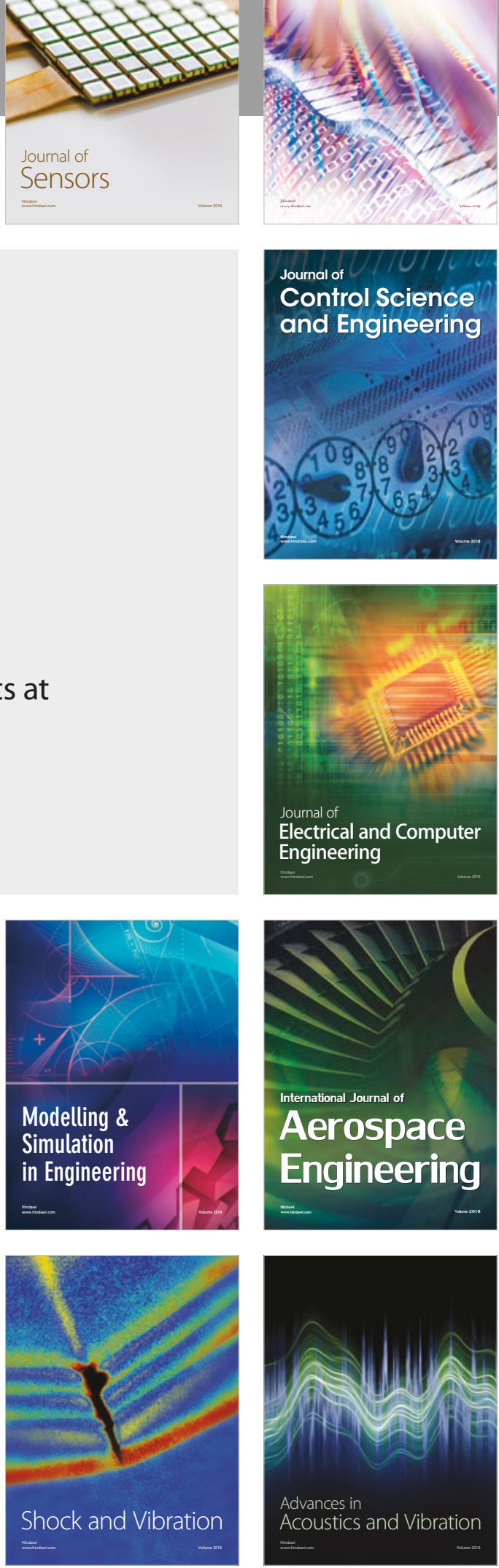